\title{
Dinotefuran-induced morphophysiological changes in the ovaries and midgut of semi-engorged females Rhipicephalus sanguineus Latreille, 1806 (Acari: Ixodidae) ticks
}

\author{
Patrícia Rosa de Oliveira ${ }^{1}$ - Rafael Neodini Remédio ${ }^{1}$ - Gervásio Henrique Bechara ${ }^{2,3}$. \\ Luis Adriano Anholeto ${ }^{1}$. Maria Izabel Camargo Mathias ${ }^{1}$
}

Received: 9 October 2015 / Accepted: 2 November 2015 / Published online: 28 November 2015

(C) Springer-Verlag Berlin Heidelberg 2015

\begin{abstract}
The present study demonstrated the effects of dinotefuran (active compound of the Protetor Pet ${ }^{\circledR}$ acaricide) in germ cells and the digestive processes of semi-engorged females of $R$. sanguineus exposed to different concentrations of the chemical. For this purpose, 120 semi-engorged females were divided into four treatment groups with 30 individuals each: group I or control (distilled water), group II (5000 ppm), group III (6250 ppm), and group IV (8334 ppm of dinotefuran). All ticks were immersed in different concentrations of dinotefuran or in distilled water for $5 \mathrm{~min}$ and then were dried and stored in biological oxygen demand (BOD) incubator for 7 days. The results show the action of this compound, exhibiting morphohistologic and histochemical changes in the oocytes and the midgut cells of individuals of different groups, which were compared with those of group I (control). The alterations occurred mainly in relation to the size of the germ cells and yolk granules; presence, quantity, size, and location of vacuoles found in the cytoplasm of these germ cells; the damage occurred in
\end{abstract}

Patrícia Rosa de Oliveira

patyrosaoliv@yahoo.com.br

1 Department of Biology, Institute of Biosciences, São Paulo State University-UNESP, Av. 24 A, n 1515, Postal Code 199, Zip Code: 13506-900 Rio Claro, SP, Brazil

2 Department of Animal Pathology, Faculty of Agronomic and Veterinary Sciences, São Paulo State University-UNESP, Via de Acesso Prof. Paulo Castellane, s/n, Zip Code:

14884-900 Jaboticabal, SP, Brazil

3 Graduate Program in Animal Science, School of Agricultural Science and Veterinary Medicine, The Pontificia Universidade Catolica do Parana-PUCPR, Rua Imaculada Conceição, 1155, Zip Code 80215-901 Curitiba, PR, Brazil the generative cells of the midgut; the size of the digestive cells; the quantity of blood elements captured, accumulated digestive wastes and digestive vacuoles found in the cytoplasm of the digestive cells of the midgut, as well as the amount and distribution of proteins, polysaccharides, lipids of all cells in both organs. So, it has demonstrated the effectiveness of dinotefuran in the reduction of fertility and digestive processes of semi-engorged females of $R$. sanguineus, data that points the possibility of employing this chemical to control these ectoparasites.

Keywords Dinotefuran · Rhipicephalus sanguineus · Tick · Acaricide $\cdot$ Neonicotinoids

\section{Introduction}

Rhipicephalus sanguineus is probably the kind of tick that is most widely distributed in the entire world (Linardi and Nagem 1973; Labruna and Pereira 2001; Szabó et al. 2001; González et al. 2004; Soares et al. 2006). Dogs are the only primary hosts needed for $R$. sanguineus maintenance in an environment. Man and other animals like horses and cattle can be found infected with $R$. sanguineus when they are in limited contact with the dog. In some parts around the world, there are reports of these ectoparasites in other medium and large size mammals, birds, and reptiles. Among mammals, we may include zebras, buffalos, camels, cats, deer, and lions. In Africa, the immature stages have more predominance in small mammals (Labruna and Pereira 2001).

In addition to direct damages caused by the tick bites, they may also act as disease vectors (Labruna and Pereira 2001). $R$. sanguineus may be the vector of Ehrlichia canis, Babesia canis, B. caballi, B. equi (Sexton et al. 1976), as well as of Hepatozoon canis (Craig 1990), Anaplasma platys (French 
and Harvey 1983), and Haemobartonella canis (Woldehiwet and Ristic 1993). Some studies have reported the possibility of their participation in the transmission of Leishmania that causes canine visceral leishmaniasis (Coutinho et al. 2005). Others indicated that $R$. sanguineus would be the vector for Coxiella burnetii in humans that causes the Q fever (Stephen et al. 1980); Rickettsia rickettsii that causes Rocky Mountain spotted fever; Rickettsia conorii-the agent of boutonneuse fever (Merle et al. 1998), of Lyme disease-like borreliosis (Yoshinari et al. 1997), and of Francisella tularensis bacteria, the agent of tularemia (Walker et al. 2000).

The main form to control these parasites still is with chemicals (through synthetic acaricides). Selection of acaricide-resistant strains of ticks and contamination of nontarget organisms, as well as the environment, are factors that have encouraged investigations that aim at improving recent acaricides and/or developing new anti-parasite products through the identification of new pesticide molecules (Nolan 1985; Crampton et al. 1999; Pruett 1999; Oliveira et al. 2008, 2009). With that approach, there is also the intention of decreasing or even replacing ineffective or inappropriate synthetic products that are currently in use.

A class of substances that has the potential of controlling several plagues and that has most increased in the market since the commercialization of pyrethroids is the neonicotinoids. This promising class presents excellent chemical and biological properties, as well as low toxicity for mammals (Nauen and Bretschneider 2002). Among them, there is dinotefuran, which is the most recent synthetized neonicotinoid and belongs to the third generation (Wakita et al. 2003, 2005; Wakita 2011). Its use is effective against a wide variety of plagues that are established in diverse kinds of cultures and against Periplaneta americana, Culex quinquefasciatus, Anophele gambiae, Aedes aegypti, among others. It can even eliminate strains resistant to other groups of insecticides, such as pyrethroids, which demonstrates its effectiveness and excellent insecticide property that eliminates a great amount of arthropod pests (Kiriyama and Nishimura 2002; Wakita et al. 2003; Corbel et al. 2004). Toxicological and ecotoxicological studies showed that dinotefuran has a very low toxicity for mammals, birds, and water animals (Kagabu 1997; Uneme et al. 1999; Wakita et al. 2005) and the environment (Wakita et al. 2005; EPA 2009; Wakita 2011). Its excellent physical-chemical, biological, and toxicological properties make dinotefuran a promising candidate to control vectors and plagues of public importance (Zaim and Guillet 2002; Wakita et al. 2005). This makes its important role clear in the current context and even stimulates more research involving its activity effects and mechanisms.

For Ctenocephalides felis felis fleas, dinotefuran has been a very efficient product (Dryden et al. 2011). However, until now, there are only few studies in literature on how to use this chemical to control the $R$. sanguineus tick.

Concerning the above information, this study aimed at determining the effects of different dinotefuran concentrations in germ and midgut cells of semi-engorged $R$. sanguineus females ticks through a morphological, histological, and histochemical study and at comparing its conclusions to the results obtained from the control group individuals, in order to understand the activity of this product in different cells and, therefore, allow the accomplishment of essential information that will help the development of new control methods of $R$. sanguineus ticks and/or improve usual and more specific control methods, which do not induce tick-resistance and are less toxic and less damaging to the environment and non-target organisms.

\section{Material and methods}

\section{Chemical substance}

\section{Synthetic: dinotefuran (CAS 165252-70-0)}

Dinotefuran is a compound of the neonicotinoid chemical class, molecular formula $\mathrm{C}_{7} \mathrm{H}_{14} \mathrm{~N}_{4} \mathrm{O}_{3}$. The chemical was obtained from the commercial acaricide Protetor Pet ${ }^{\circledR}$, produced by "Ouro Fino Saúde Animal”, Cravinhos, SP, Brazil, in tubes of $0.48 \mathrm{~mL}$, concentration $25 \%$, for animals up to $5.0 \mathrm{~kg}$.

\section{R. sanguineus ticks (Latreille, 1806)}

Semi-engorged $R$. sanguineus females, weighing $27 \mathrm{mg}$ on average (about 5 days of feeding), were used throughout the experiment. They were supplied by the tick colony maintained under controlled conditions $\left(28^{\circ} \mathrm{C}, 85 \%\right.$ humidity, and 12-h photoperiod) in a biological oxygen demand (BOD) incubator, in a room of the Animal Facility of the Department of Biology-UNESP, Rio Claro Campus/São Paulo, Brazil. Semi-engorged females were obtained after unfed $R$. sanguineus couples ( 25 couple/infestation) were allowed to feed on naive New Zealand white rabbits following Bechara et al. (1995). The semi-engorged stage of the females was chosen due to the high parasitary efficiency in this phase.

\section{Hosts}

New Zealand White rabbits, weighing between 3 and $3.5 \mathrm{~kg}$, were used as hosts. Rabbits were obtained from the Animal Facility of UNESP - Botucatu Campus/São Paulo-Brazil and housed in the Animal Facility of UNESP-Rio Claro Campus/São Paulo-Brazil. Animals did not have prior contact with ticks or acaricides and were kept under controlled conditions. During the entire experiment, animals were maintained in cages and received water and rabbit food ad libitum. 
The Ethics Committee for Animal Experimentation of UNESP/SP/Brazil, protocol nº334/2014, approved this study.

\section{Dinotefuran dosage}

The initial concentration of dinotefuran was defined based on the recommendations of manufacturer-product label of Protetor Pet ${ }^{\circledR}$. Several doses were evaluated in preliminary tests (pilots) by diluting dinotefuran (Protetor Pet ${ }^{\mathbb{R}}$ ) in distilled water $(0$ to $50 \%)$. After this bioassay, the efficacy of dinotefuran and the level of susceptibility of the semiengorged females were evaluated, and the lethal concentration $\mathrm{LC}_{50}$ determined was $10182.253 \mathrm{ppm}$. In this study, the concentrations corresponded to 5000,6250, and $8334 \mathrm{ppm}$ of dinotefuran. All the concentrations of dinotefuran were kept in labeled volumetric flasks until the tests. Each treatment was conducted in duplicate.

\section{Experimental model}

$R$. sanguineus semi-engorged females were divided into three treated groups: group II (5000 ppm of dinotefuran), group III (6250 ppm of dinotefuran), and group IV (8334 ppm of dinotefuran). The control group was exposed only to the placebo (distilled water).

The 120 semi-engorged females of $R$. sanguineus, after being washed in a sieve with tap water, were dried on soft absorbent paper. After that, 90 females were divided into three groups of 30 females (30 females for each concentration-2 groups with 15 individuals - duplicates) and immersed for 5 min in Petri dishes containing the above different concentrations of dinotefuran. The control group was also composed of 30 females that had been immersed in distilled water for the same period. Ticks were then dried in absorbent paper and placed in the BOD incubator $\left(28 \pm 1{ }^{\circ} \mathrm{C}, 80 \%\right.$ relative humidity and $12 \mathrm{~h}$ photoperiod) for 7 days. The observation period was established because, frequently, the effect of acaricides is not immediate but acts slowly on the physiology of the individual analyzed (Roma et al. 2010).

After 7 days of monitoring, all the semi-engorged females were forwarded to histological and histochemical techniques.

\section{Methods}

\section{Histology}

All semi-engorged females maintained in the refrigerator for thermal shock anesthesia were dissected in a phosphate buffered saline-PBS solution $\left(\mathrm{NaCl} 7.5 \mathrm{~g} / \mathrm{L}, \mathrm{Na}_{2} \mathrm{HPO}_{4} 2.38 \mathrm{~g} / \mathrm{L}\right.$ e $\mathrm{KH}_{2} \mathrm{PO}_{4} 2.72 \mathrm{~g} / \mathrm{L}$ ).

The ovaries and midguts were fixed for $24 \mathrm{~h}$ in $4 \%$ paraformaldehyde, dehydrated in ethanol, embedded in
Leica resin for $24 \mathrm{~h}$ at $4{ }^{\circ} \mathrm{C}$ and transferred to plastic molds previously filled with polymerized Leica resin. After resin polymerization, all the blocks were sectioned at $3-\mu \mathrm{m}$ thickness slices using a Leica RM 2255 microtome (Bio $\mathrm{Rad}$ ) and stained with hematoxylin and eosin, following routine histological procedures. The glass slides were examined in a Motic BA300 photomicroscope.

This device and other equipments were from the Histology Laboratory of the Biology Department at the Biosciences Institute, UNESP, Rio Claro Campus/São Paulo, Brazil.

\section{Histochemistry}

To detect changes such as presence or absence, frequency, distribution of proteins, polysaccharides, and lipids in the semi-engorged females of control and Dinotefuran-treated groups, histological sections were prepared for the histochemical techniques listed below.

\begin{abstract}
Alcian blue-PAS technique for acid and neutral polysaccharide detection (according to McManus 1948; Junqueira and Junqueira 1983) Semi-engorged females were fixed with aqueous Bouin's solution for $12 \mathrm{~h}$, and the histological sections were rehydrated for $1 \mathrm{~min}$ in distilled water. The material was then stained with $1 \%$ Alcian blue in $3 \%$ acetic acid for $30 \mathrm{~min}$ and washed in distilled water. The sections were transferred to $1 \%$ periodic acid solution for $5 \mathrm{~min}$ and washed in distilled water again. After $30 \mathrm{~min}$ in Schiff's reagent, the material was washed with sulfur water and rinsed with tap water for $10 \mathrm{~min}$. After drying, the slides were clarified with xylol and mounted in Canada balsam to be later observed and photographed with a Motic BA 300 photomicroscope.
\end{abstract}

\section{Bromophenol blue staining for protein detection} (according to Pearse 1985) Semi-engorged females were fixed with $4 \%$ paraformaldehyde. All slides were stained with bromophenol blue for $2 \mathrm{~h}$ at room temperature. Afterwards, they were washed with $0.5 \%$ acetic acid for $5 \mathrm{~min}$ and tap water for $15 \mathrm{~min}$; slides were quickly immersed in tertiary butyl alcohol, allowed to dry at room temperature, clarified, and mounted in Canada balsam.

Baker's method for lipid detection (according to Baker 1946) The semi-engorged females were fixed with formol calcium for $15 \mathrm{~h}$ and transferred to dichromate calcium for $18 \mathrm{~h}$. Afterwards, they were washed with distilled water and the slides immersed in hematein for $5 \mathrm{~h}$. The material was rinsed, differentiated in Weigert's solution, and washed with distilled water. After drying, slides were mounted with glycerin and covered with cover slips. 


\section{Results}

\section{Histology}

Ovary

Control group The results obtained in the ovaries of semiengorged females from the control group are the same described by Oliveira et al. (2005). A summary of the main characteristics of the ovaries from female $R$. sanguineus ticks is presented as follows.

The $R$. sanguineus ovary is composed of a wall of epithelial cells and of a great number of oocytes in five development stages, which are found fixed to the wall through a mobile pedicel (Oliveira et al. 2005).

Oocytes I are small elliptical cells with a germ vesicle, which have a very evident nucleolus occupying a great part of the central cytoplasm. This central cytoplasm has a homogeneous aspect without the presence of granulations. A thin plasmic membrane (Fig. 1a) surrounds these oocytes. Oocytes II are bigger than the first ones, are elliptical, and have a central germ vesicle. A thin and homogenous cytoplasmic granulation is found in them. They are also surrounded by a thin plasmic membrane (Fig. 1g). Oocytes III have medium size, and their shapes vary from round to elliptical. The germ vesicle occupies the oocyte pole directed towards the pedicel. These oocytes have a thinner plasmic membrane than the previous stages. The cytoplasm is full of yolk granules in several sizes, in which the smaller ones occupy the central area and the bigger ones, the periphery (Fig. $1 \mathrm{~m}$ ). Oocytes IV are bigger than type III. They are round and the germ vesicle is not always seen, and when present, it occupies the pole of the oocyte directed to the pedicel. In this stage, chorium deposition begins and causes a thickening of the oocyte wrap. The cytoplasm presents many yolk granules of several sizes that are randomly distributed (Fig. 1q). Oocytes V are the biggest germ cells, with round shape, and the germ vesicle can no longer be seen due to the big and numerous cytoplasmic granules. The chorium is thick and is fully deposited (Fig. 1u).

Group II Individuals exposed to 5000 ppm dinotefuran present oocytes with few morphological alterations when compared with those of the control group.

Oocytes I present small vacuoles that are weakly and strongly stained, especially around the germ vesicle (Fig. 1b, e). Oocytes II also have few and small vacuoles occupying the region near the germ vesicle. In some of these oocytes, there is a vacuolated area that surrounds the entire germ vesicle and that still points towards the pedicel, reducing the amount of yolk granules that were previously found in these places (Fig. 1h, k). Oocytes III exhibit modifications in their original shape for showing small folds in their membrane (Fig. 1n). Vacuolated regions are distributed around the germ vesicle and periphery towards the pedicel. Rare small and round vacuoles can also be seen in the cytoplasm between the yolk granules (Fig. 1n). No alterations are found in oocytes IV of individuals exposed to treatment with this concentration of dinotefuran (Fig. 1r). Oocytes V only presented rare and small folds in their membranes (chorium and plasmic membrane) (Fig. 1v).

Group III The individuals of treatment group III presented a greater number of changed oocytes when compared to those of the previous group.

Oocytes I show the same characteristics described in this same stage at group II (Fig. 1c). Oocytes II show modifications from their original shape since they have an irregular morphology. They have large vacuolated regions in almost $50 \%$ of the cell, showing great empty spaces around the germ vesicle and in the peripheral region towards the pedicel (Fig. 1i). Oocytes III present small round vacuoles in the cytoplasm among the yolk granules, especially near the periphery (Fig. 10). In oocytes IV of individuals exposed to $6250 \mathrm{ppm}$ dinotefuran, morphological alterations are not seen either (Fig. 1s). Oocytes V present changes in their shape and cytoplasm. These oocytes have an irregular morphology due to the presence of several folds throughout its entire wrap (Fig. 1w). Cytoplasmic vacuoles are found in the periphery, surrounding the entire cell. Some yolk granules seem broken, releasing content to the cytoplasm (Fig. 1w).

Group IV Ovaries of group IV individuals present several oocytes with great histological alterations when compared to those from control group and groups II and III.

Oocytes I present similar characteristics to the ones found in the same stage as the previous groups, but they also have an irregular morphology with great cytoplasmic vacuoles that occupy a large part of the cytoplasm and dislocate the germ vesicle to regions closer to the cell periphery (Fig. 1d, f).

Oocytes II have an extensive vacuolation in over $50 \%$ of the cell, especially in regions near the pedicel, and they restrict the area occupied by yolk granules. Rare folds in their membranes are also found (Fig. 1j, 1).

Oocytes III suffer changes in their morphology due to the presence of numerous folds in their wrap. Cytoplasmic vacuolation in about $50 \%$ of the cell is also seen, mainly in regions near the pedicel (Fig. 1p).

Oocytes IV concentrate round vacuoles in the central region near the germ vesicle and among the yolk granules (Figs. 1t and 2p).

Oocytes V are smaller than the others from previous groups. They present large yolk granules, but less dense 
Fig. 1 Histological sections of dinotefuran-treated

Rhipicephalus sanguineus ovary. $\mathbf{a}-\mathbf{x}$ Hematoxylin and eosin (HE) staining. a, g, m, q, u Control group. $\mathbf{b}, \mathbf{e}, \mathbf{h}, \mathbf{k}, \mathbf{n}, \mathbf{r}, \mathbf{v}$ Group II (5000 ppm). c, i, o, s, w Group III (6250 ppm). d, f, j, l, p, t, $\mathbf{x}$ Group IV (8334 ppm). I oocyte I, II oocyte II, III oocyte III, IV oocyte IV, $V$ oocyte V, ch chorium, ep ovary epithelium, $g v$ germ vesicle, $n u$ nucleolus, $p$ pedicel, pm plasmic membrane, $y g$ yolk granules, $v$ vacuoles. Bars: $\mathbf{a}-\mathbf{t}=50 \mu \mathrm{m} ; \mathbf{u}-\mathbf{w}=100 \mu \mathrm{m}$; $\mathbf{x}=50 \mu \mathrm{m}$
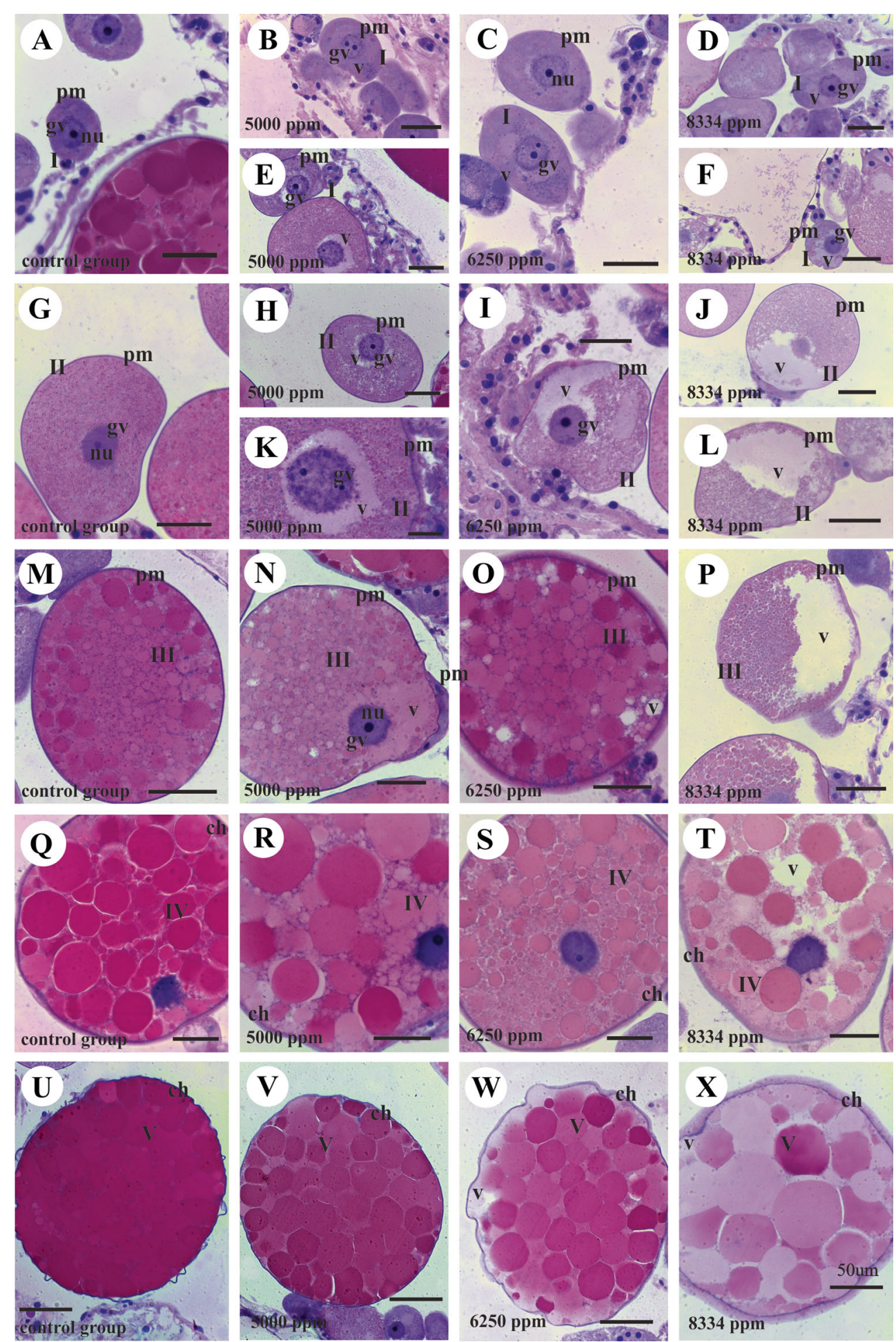
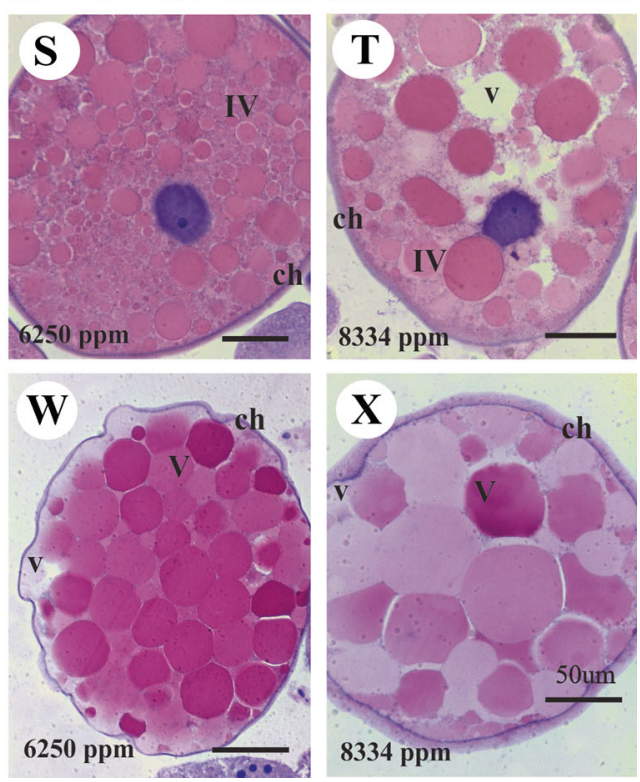

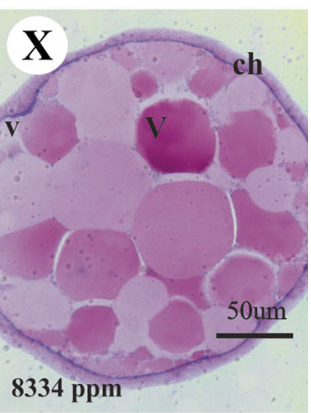

ones, and folds throughout the entire chorium. Some vacuoles may be found around the large yolk granules and others in the periphery, surrounding the entire cell (Figs. 1x, 2n, 3, and 4). In the periphery of some oocytes, yolk granules that are broken releasing content to the cytoplasm can also be seen (Fig. 1x).
Oocytes III, IV, and V show yolk granules with smaller size than those found in the previous groups (Fig. 1p, t, x).

The wall of the ovary was damaged only in this treatment group. The epithelium, instead of being represented by small cubic cells with round nuclei like in the previous groups, now is extremely fragile and delicate, showing 
Fig. 2 Histological sections of dinotefuran-treated

Rhipicephalus sanguineus ovary. $\mathbf{a}-\mathbf{v}$ PAS staining. a, e, $\mathbf{k}, \mathbf{o}, \mathbf{s}$ Control group. $\mathbf{b}, \mathbf{f}, \mathbf{i}, \mathbf{l}, \mathbf{p}, \mathbf{t}$ Group II (5000 ppm). c, g, j, m, q, u, w Group III (6250 ppm). d, h, n, r, v Group IV (8334 ppm). I oocyte I, II oocyte II, III oocyte III, $I V$ oocyte IV, $V$ oocyte V, ch chorium, $e p$ ovary epithelium, $g v$ germ vesicle, $n u$ nucleolus, $p$ pedicel, $p m$ plasmic membrane, $y g$ yolk granules, $v$ vacuoles. Bars: $\mathbf{a}-\mathbf{r}=50 \mu \mathrm{m} ; \mathbf{s}-\mathbf{w}=100 \mu \mathrm{m}$ $\mathbf{v}=50 \mu \mathrm{m}$
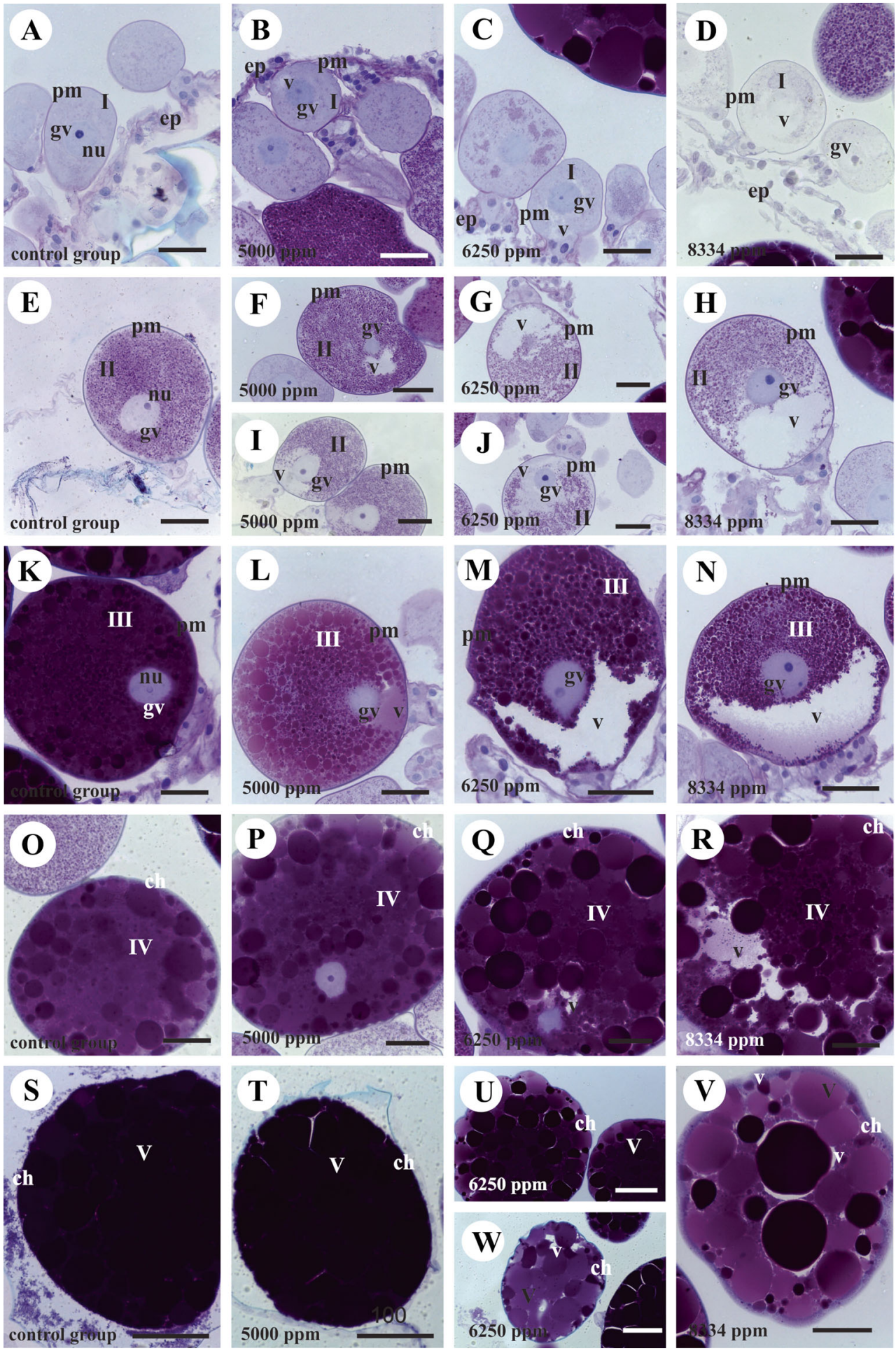

vacuolated cells with flattened morphology and pyknotic nucleus (Fig. 1f, t).

\section{Midgut}

Control group The midgut of semi-engorged $R$. sanguineus females from the control group consists of an epithelial wall supported on a basal membrane and a thin layer of muscular tissue (Fig. 5a, e, i, m, q). The epithelial wall is pseudostratified and formed by digestive and generative cells (Fig. 5a, e, i, m, q).

The generative cells (stem cells) are small with shapes varying from cubical to prismatic ones and completely supported on the basal membrane. Their nucleus is small, central, 
Fig. 3 Histological sections of dinotefuran-treated

Rhipicephalus sanguineus ovary. a-t Baker staining. a, e, i, m, q Control group. $\mathbf{b}, \mathbf{f}, \mathbf{j}, \mathbf{n}, \mathbf{r}$ Group II (5000 ppm). c, g, k, o, s Group III (6250 ppm). d, h, l, p, t Group IV (8334 ppm). I oocyte I, II oocyte II, III oocyte III, $I V$ oocyte IV, $V$ oocyte V, ch chorium, $e p$ ovary epithelium, $g v$ germ vesicle, $n u$ nucleolus, $p$ pedicel, pm plasmic membrane, $y g$ yolk granules, $v$ vacuoles. Bars: $\mathbf{a}-\mathbf{p}=50 \mu \mathrm{m} ; \mathbf{q}-\mathbf{s}=100 \mu \mathrm{m}$; $\mathbf{t}=50 \mu \mathrm{m}$
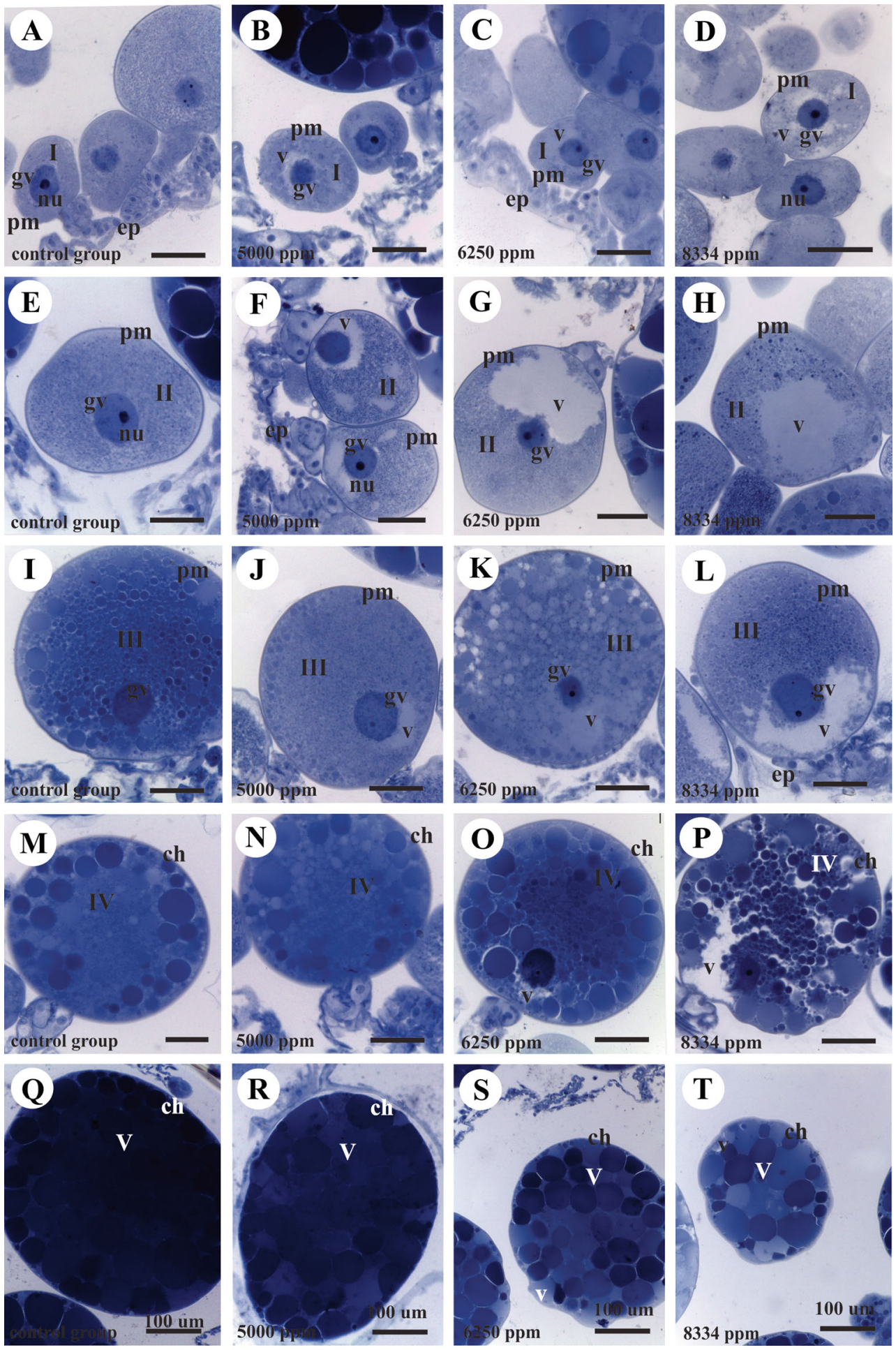

round, and with condensate chromatin (Fig. 5i, m). The cytoplasm is full of round and little stained regions, probably vacuoles and/or lipid droplets (Fig. 5i, m). A plasmic membrane wraps them externally (Fig. 5i, m).

The digestive cells are large and quite numerous (Fig. 5a, e, i, m, q). Throughout the stages of a life cycle and of the tick engorgement process, these cells undergo several development stages. In the semi-engorged $R$. sanguineus females in the control group, three stages of digestive cells were detected. There is the sessile digest cells, which are columnar, full of endosomes with blood (mainly red cells) that was ingested from the host during engorgement and digestive vacuoles of several sizes, shapes, and strongly eosin-stained (Fig. 5a, e, i, m, q); 
Fig. 4 Histological sections of dinotefuran-treated

Rhipicephalus sanguineus ovary. a-v Bromophenol blue staining. $\mathbf{a}, \mathbf{e}, \mathbf{i}, \mathbf{o}, \mathbf{s}$ Control group. $\mathbf{b}, \mathbf{f}, \mathbf{j}, \mathbf{p}$, t Group II (5000 ppm). c, g, k, m, q, u Group III (6250 ppm). d, h, l, $\mathbf{n}, \mathbf{r}, \mathbf{v}$ Group IV (8334 ppm). I oocyte I, II oocyte II, III oocyte III, $I V$ oocyte IV, $V$ oocyte V, ch chorium, $e p$ ovary epithelium, $g v$ germ vesicle, $n u$ nucleolus, $p$ pedicel, $p m$ plasmic membrane, $y g$ yolk granules, $v$ vacuoles. Bars: $\mathbf{a}-\mathbf{r}=50 \mu \mathrm{m} ; \mathbf{s}-\mathbf{u}=100 \mu \mathrm{m}$ $\mathbf{v}=50 \mu \mathrm{m}$
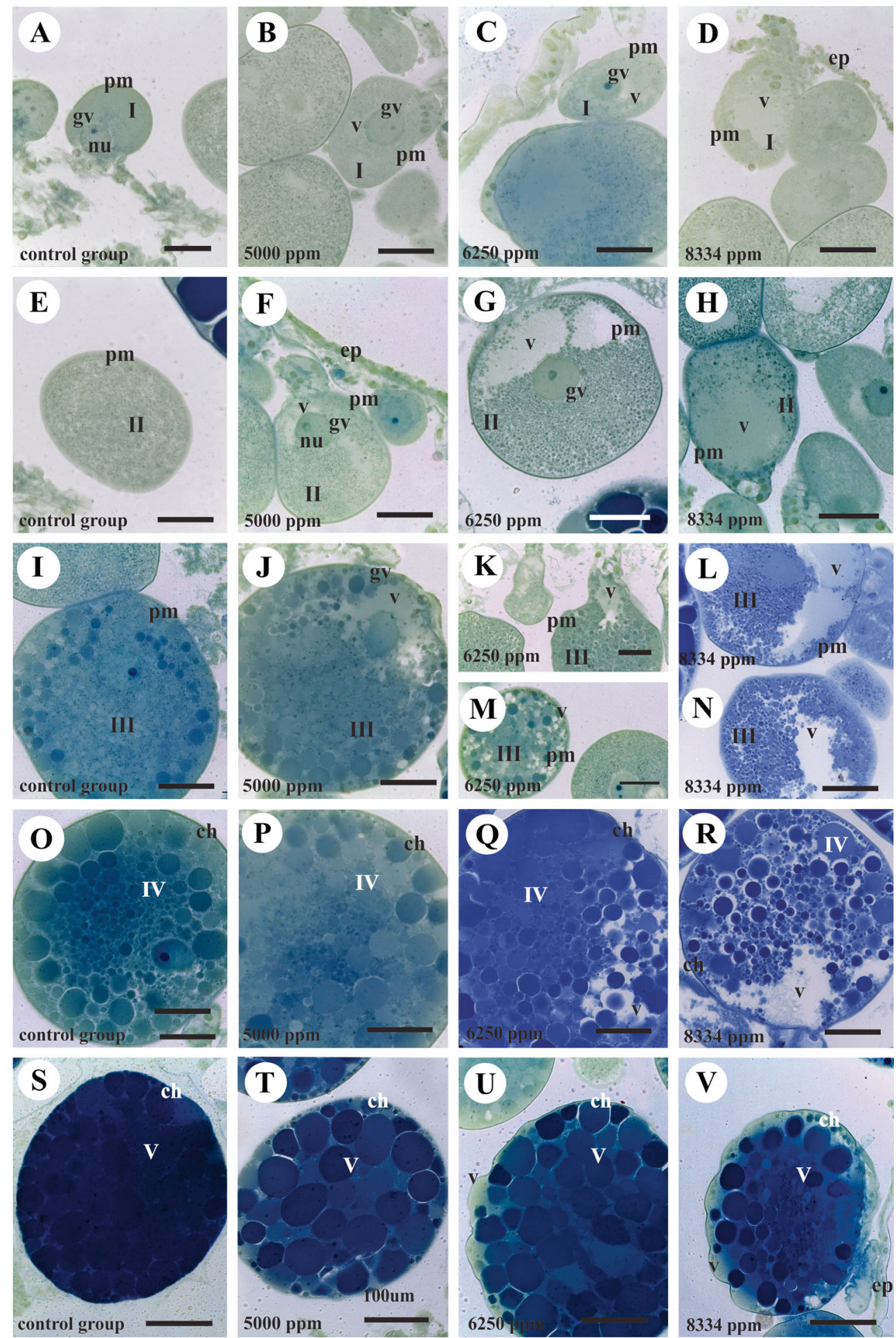

the residual sessile digest cells, with a cytoplasm projected towards the lumen and almost no contact with the basal membrane; in addition, the cytoplasm of such cells has many endosomes and digestive vacuoles (Fig. 5a, e, i, m, q). Finally, there is also the detached digest cells, which have spherical shape and are free in the midgut lumen, and after they have being disengaged from the basal membrane, several endosomes, digestive vacuoles and hematin residual bodies (final product of intracellular digestion that has been accumulated inside the cell) occupy their cytoplasm (Figs. 5a, e). The nucleus of all digestive cells is large and round; however, its limit is hardly seen, since with the 
Fig. 5 Histological sections of dinotefuran-treated

Rhipicephalus sanguineus midgut. a-t Hematoxylin and eosin (HE) staining. a, e, i, m, q Control group. $\mathbf{b}, \mathbf{f}, \mathbf{j}, \mathbf{n}, \mathbf{r}$ Group II (5000 ppm). c, g, k, o, s, Group III (6250 ppm). d, h, l, p, t Group IV (8334 ppm). $s d c$ sessile digest cells, $r d c$ residual sessile digest cells, $d d c$ detached digest cells, $l$ lumen, $m$ muscular tissue, stc stem cells (generative cells), $n$ nuclei, $p m$ plasmic membrane, $v$ vacuoles. Bars: $\mathbf{a}-\mathbf{c}=200 \mu \mathrm{m}$; d, $\mathbf{e}=100 \mu \mathrm{m} ; \mathbf{f}=50 \mu \mathrm{m} ; \mathbf{g}$, $\mathbf{h}=100 \mu \mathrm{m} ; \mathbf{i}-\mathbf{I}=50 \mu \mathrm{m} ; \mathbf{m}$, $\mathbf{o}=20 \mu \mathrm{m} ; \mathbf{p}=50 \mu \mathrm{m} ; \mathbf{q}-\mathbf{t}=20 \mu \mathrm{m}$
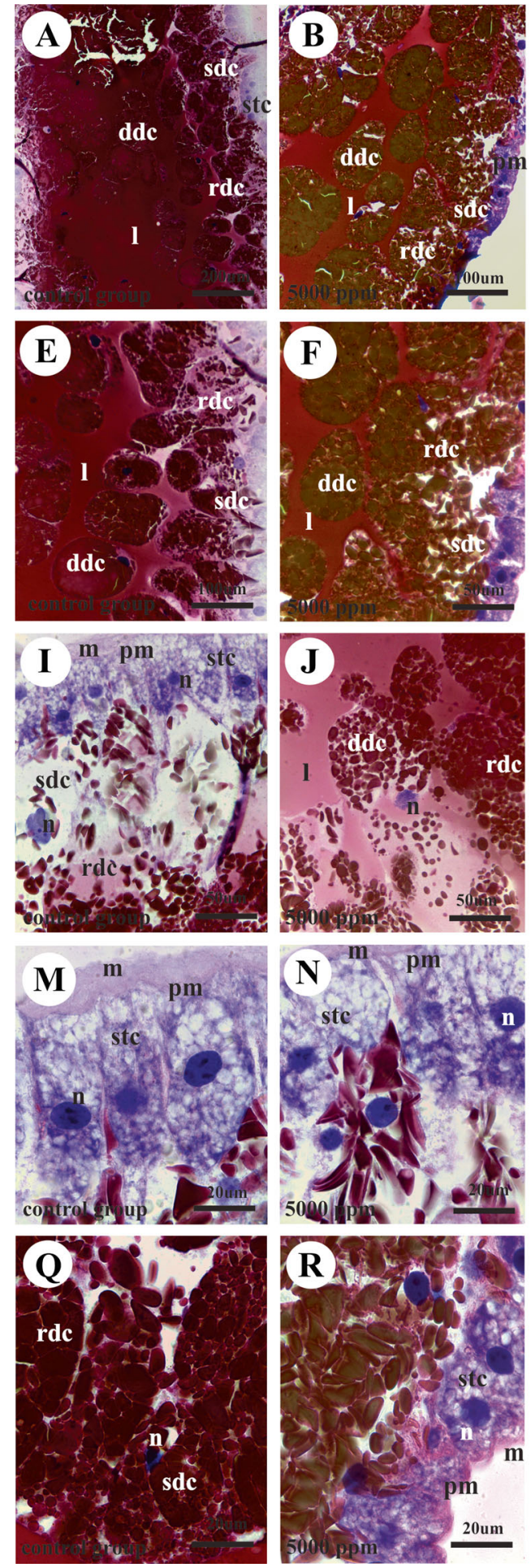
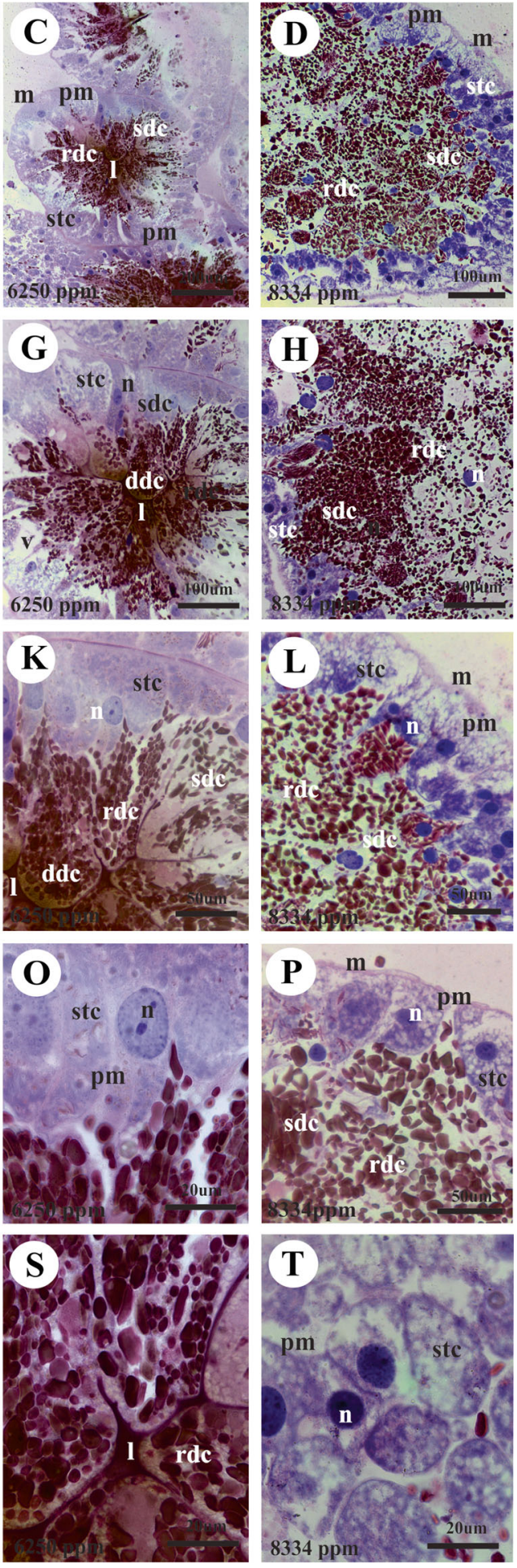

digestive process advance, different "granulations" of several shapes and sizes appear in the cytoplasm and cover them (Fig. 5a, e, i, m, q).

The midgut lumen of individuals from the control group has a great amount of blood; detached digest cells that are free in the lumen; apical cytoplasm projection of the residual sessile digest cells; and residues from digestive processes, released by exocytosis and/or lysis of digestive cells present in another stage of digestion or of the life cycle that will be incorporated to the fecal material (Fig. 5a, e).

Group II The midgut of semi-engorged females exposed to $5000 \mathrm{ppm}$ dinotefuran did present modifications neither in the morphology nor in the quantity of their cells. Both the 
generative (stem cells), and all the digestive cells, the sessile digest cells, the residual sessile digest cells, detached digest cells, the muscular layer, and the lumen continue with the same characteristics found in the control group (group I) (Figs. 5b, f, j, n, r).

Group III The midgut of semi-engorged females from group III presented significant alterations compared to the control group. Alterations happened in the generative cells (stem cells) in all the stages of digestive cells and in the lumen. The generative cells (stem cells) have irregular shape (Fig. 5c, g, k, o). In some of these cells, the presence of vacuoles with several shapes and sizes throughout the entire cytoplasm can also be seen (Figs. 5c, g, k, o). The digestive cells are less numerous. The digestive cells, sessile digest cells and residual sessile digest cells, have less eosin-stained, smaller, with less frequent endosomes and digestive vacuoles in the cytoplasm (Fig. 5c, g, k, o, s). These cells seem to be more projected towards the lumen. The digestive cells, detached digest cells, are hardly seen and also accumulate a smaller number of endosomes, digestive vacuoles, and hematin residual bodies. They are all not quite eosin-stained (Fig. $5 \mathrm{~g}$ ).

The midgut lumen of individuals from this group is small, with little blood, and filled with digestive cells, especially by apical projections of the residual sessile digest cells (Fig. 5c, g, k, s).

Group IV The semi-engorged females from group IV show great histological alterations compared to those from the control, II, and III groups. These changes are seen in generative cells (stem cells), in digestive cells, and in the midgut lumen.

The generative cells (stem cells) are irregular and some of them are even twisted. The cytoplasmic vacuolation is developed mainly in the basal region of the cell and near the digestive cells (Figs. 5d, h, 1, p, t).

The digestive cells, sessile digest cells and residual sessile digest cells, have fewer endosomes and digestive vacuoles in the cytoplasm if compared to individuals from previous groups (Fig. 5d, h, 1, p). Both the first and second are slightly stained with EH. Such decrease in the size of endosomes and digestive vacuoles allowed observing the nucleus, which is still large and round. The cell limit of these two cells is hardly detected, and therefore, their cytoplasm seems to belong to only one cell (Fig. 5d, h, 1, p). These two stages of digestive cells seem to be occupying regions that were previously occupied by detached digest cells, i.e., more projected towards the lumen. It is not possible to differentiate the detached digest cells.

The midgut lumen does not have blood and seems to have been filled with digestive cells or sessile digest cells or the larger apical projections of the residual sessile digest cells or even those that were disengaged from the basal membrane (Fig. 5d, h).

\section{Histochemistry}

Alcian blue-PAS staining for acid and neutral polysaccharide detection

\section{Ovary}

Control group

The use of a PAS histochemical test reveals a high presence of polysaccharides in the ovary of individuals from the control group. Results obtained here in the ovaries from semi-engorged females from the control group are the same described by (Oliveira et al. 2005). The main characteristics are epithelial wall and oocytes I present weak cytoplasmic positivity (Fig. 2a); oocytes II show cytoplasm with a moderate positive and homogeneous thin granulation (Fig. 2e); oocytes III present strong positive cytoplasmic granules of several sizes, where the larger ones are mainly placed in the periphery and the smaller ones, in the central region of the oocyte (Fig. 2k); oocytes IV with strong positive yolk granules of several sizes; and oocytes V, where the presence of large strong positive granules is seen occupying the entire cytoplasm (Fig. 2s) (Oliveira et al. 2005).

Group II

This histochemical test shows a smaller amount of polysaccharides in the ovary of individuals from this group compared to the control group, mainly in oocytes I, II, and III because of the cytoplasmic vacuolation beginning. Oocytes I continue presenting weak positivity to the PAS (Fig. 2b). Oocytes II have a moderately positive thin granulation (Fig. 2f, i), and oocytes III present strongly positive yolk granules located in the central region and large strongly positive granules in the peripheral region. However, there is the appearance of vacuolated regions that negatively react to the test (Fig. 21). Oocytes IV and V present similar reactions to the control group (Fig. 2p, t). Group III

Application of this histochemical test reveals the presence of a smaller amount of polysaccharides in all oocytes of the ovary from females exposed to this concentration of dinotefuran. Oocytes I persist in the weakly positive reaction (Fig. 2c). In the oocytes II and III, the distribution of this element is similar to that one found in oocytes from individuals of the treatment group II (Fig. $2 g$, j, $\mathrm{m})$. Nevertheless, there is an increase in the cytoplasmic areas negative to the test (Fig. 2g, j, m). Oocytes IV now show some small vacuolated areas negative to the test near the germ vesicle (Fig. 2q). With regard to the oocytes $\mathrm{V}$, in addition to all morphological alterations already described, they also present granules with smaller positivity to PAS, especially near the peripheral region, as well as small vacuoles negative to the test (Fig. $2 \mathrm{u}$, w). Group IV 
The histochemical test to detect polysaccharides shows a great decrease in the quantity of this element in the ovary of individuals from group IV when compared to the other groups.

Oocytes I have markings similar to those found in these same oocytes from the other groups, i.e., a positive weak reaction (Fig. 2d). In oocytes II and III, the yolk granules continue reacting and occupying the same regions as the ones found in the treatment groups II and III. However, in this group, these oocytes show extensive vacuolated regions negative to PAS (Fig. $2 \mathrm{~h}, \mathrm{n}$ ).

Oocytes IV present a strongly positive reaction in yolk granules and vacuoles that do not react to the test in the central region near the germ vesicle and among the granules (Fig. 2r).

Oocytes $\mathrm{V}$ present a less intense positive reaction in the large yolk granules and also in the chorium. Small cytoplasmic vacuoles that are negative to the test both around the great yolk granules and in the peripheral region have also been detected (Fig. 2v).

With regard to the epithelial wall of the ovary, instead of presenting a weak positive reaction, it no longer reacts to the PAS, which shows the decrease of polysaccharides found in this epithelium when compared to other groups (Fig. 2d).

\section{Midgut}

Through the histochemical test, a small amount of polysaccharides is found in the midgut of females from all the groups, seen by the weak positive reaction in this organ. The midgut cells of the treatment groups II, III, and IV have similar markings to those from the control group. The weak positivity in the organ, in general, determined clear markings, which were not shown here.

\section{Baker's technique for lipid detection}

\section{Ovary}

Control group

Through this histochemical test, a high marking for lipid elements in the ovary of semi-engorged females from the control group is found. These results are equivalent to the ones obtained and described by Oliveira et al. (2005). The main characteristics are epithelial wall and oocytes I with a homogeneous and moderately positive cytoplasm (Fig. 3a); oocytes II with a positive thin granulation homogeneously distributed into all the cytoplasm (Fig. 3e); oocytes III, cytoplasm with small and strongly positive yolk granules in the center and larger granules located mainly in the cell peripheral region (Fig. 3i); oocytes IV, cytoplasm with many positive granules and sizes increasing from the central region to the periphery and chorium with moderate positivity (Fig. $3 \mathrm{~m}$ ); oocytes $\mathrm{V}$ present the cytoplasm full of great strongly positive yolk granules and chorium (Fig. 3q).

The nuclei of all cells (including oocytes, pedicels, and cells from the wall of the ovary), as well as nucleolus, are stained due to the use of hematein, which is a solution obtained through hematoxylin oxidation (Fig. $2 \mathrm{~g}$ ).

Group II

This test reveals that all oocytes from treated individuals with this concentration of dinotefuran continue reacting positively. Nevertheless, oocytes I, II, and III have already began presenting vacuolated areas that are negative to the test, especially near the germ vesicle and pedicel, which evidences the beginning of the decrease of this element in the ovary of treated individuals (Fig. 3b, f, j). Histochemically speaking, oocytes IV and V present similar reactions to those found in these stages from the control group (Fig. 3n, r).

Group III

In most oocytes from individuals exposed to treatment with $6250 \mathrm{ppm}$ dinotefuran, a positive reaction to the test was found. Oocytes I continue presenting a moderate positive reaction (Fig. 3c), and oocytes II and III have the same characteristics described at group II, with the exception of the largest cytoplasmic areas that are negative to the test, probably due to the presence of vacuoles (Fig. 3g, k). In this group, even oocytes IV show small vacuoles that are negative to the test occupying a region near the germ vesicle (Fig. 3o). On the other hand, oocytes $\mathrm{V}$ present yolk granules with lower positivity and small vacuoles that are negative to the test in a region near the cell periphery (Fig. 3s).

Group IV

The histochemical test to detect lipids highlights the high decrease for elements in the ovary of females from group IV. Oocytes I, II, and III have extensive vacuolated regions that are negative to the test, which occupied a great part of the cytoplasm. The yolk granules, when present, have the same histochemical reaction and are distributed similarly to other groups (Fig. 3d, h, l). Oocytes IV present strongly positive yolk granules among vacuolated areas that are negative to the test (Fig. 3p). Oocytes V exhibit large granules of strong, moderate, and weak positivity, a moderately positive chorium, and small negative vacuoles to the test in the peripheral region (Fig. 3t). The epithelial wall reacts weakly to the test (Fig. 31).

\section{Midgut}

Control group This histochemical test shows the presence of great amount of lipids in the cells of the midgut from semiengorged $R$. sanguineus females. 
The generative cells (stem cells) exhibit small round regions of moderate positivity through the cytoplasm, possibly lipid droplets (Fig. 6a, e, i, m). The plasmic membrane is also moderate positive to the test (Figs. 6a, e, i, m).

The sessile digest cells and residual sessile digest cells have several large endosomes and digestive vacuoles that are strongly positive throughout the entire cytoplasm, which also cover the nucleus of these cells (Fig. 6a, e, i, m). The detached digest cell, on the other hand, besides presenting a strongly positive reaction in the endosomes and digestive vacuoles, also showed a negative reaction to the test, especially in the several residual bodies of hematin that occupy its cytoplasm (Fig. 6a, e, i, m). The nucleus of these cells is also covered by endosomes, digestive vacuoles, and hematin residual bodies (Fig. 6a, e, i, m).

The midgut lumen of individuals from the control group presents a strong positive reaction, except in the regions that are negative to the test, occupied by several detached digest cells and by residues from the digestive processes (Fig. 6a, e, i, m).

The nuclei of generative (stem cells) and muscular cells are stained due to the use of hematein, a solution obtained from the oxidation of hematoxylin (Fig. 6a, e, i, m).

Group II Baker's histochemical test reveals that the midgut of semi-engorged females exposed to $5000 \mathrm{ppm}$ dinotefuran presents a similar reaction to the control group, i.e., strong positivity for lipids in most cells and negative reaction in the hematin residue bodies found in the detached digest cells (Fig. 6b, f, j, n).

Group III Results show the presence of a great quantity of lipids in the midgut of semi-engorged $R$. sanguineus females of group III. However, the positivity found here is lower than that one found in individuals from the other groups.

Some generative cells (stem cells) show large and small vacuoles that are negative to the test occupying its cytoplasm (Fig. 6c, g, o). The digestive cells, sessile digest cells and residual sessile digest cells, present endosomes and digestive vacuoles that strongly react to the test for detecting lipids but in a smaller quantity than those from the other groups through the cytoplasm (Fig. 6c, g, k, o). The digestive cells, detached digest cells, are rarely seen, and when they are found, they show a smaller number of endosomes and digestive vacuoles that are strongly positive and hematin residual bodies that are negative to the test. The midgut lumen is small, but with a strong positive marking, and filled with endosomes and digestive vacuoles that are strongly positive, located in the apical projections of the residual sessile digest cells (Fig. 6c, g, k, o).

Group IV Midgut of semi-engorged females from group IV presents a decrease in the quantity of lipids when compared to those of the other groups.
Generative cells (stem cells), which had small round regions of moderate positivity (lipid droplets), hardly ever present them (Fig. 6d, h, 1, p). In this group, these cells show many round vacuoles negative to the test, especially in the basal region and in the one near the digestive cells (Fig. 6d, h, 1, p).

Digestive cells, sessile digest cells and residual sessile digest cells, have few endosomes and strongly positive digestive vacuoles in the cytoplasm (Fig. 6d, h, 1, p). On the other hand, the detached digest cells were not found.

The midgut lumen does not have blood and seems to have the sessile digest cells and the largest apical projections of the residual sessile digest cells with endosomes and vacuoles of strong positivity (Fig. 6d, h, 1, p).

\section{Bromophenol blue staining for protein detection}

\section{Ovary}

\section{Control group}

Using the bromophenol blue histochemical test, the presence of a great amount of protein elements in the ovary of semi-engorged $R$. sanguineus females from the control group is seen. As already stated, Oliveira et al. (2005) have already described these results. In order to detect proteins, the main characteristics are weakly positive epithelial wall and oocytes I (Fig. 4a); oocytes II showing thin positive granulation distributed uniformly through the cytoplasm (Fig. 4e); oocytes III, cortex with strongly positive small yolk granules in the central region and the largest ones of strong positivity in the periphery (Fig. 4i); oocytes IV, cytoplasm with strong positive yolk granules of several sizes (Fig. 4o); oocytes V, high quantity of big strong positive granules that occupy the entire cytoplasm (Fig. 4s).

The germ vesicle, nuclear membrane, and plasmic membrane have a weak reaction (Fig. $4 \mathrm{a}, \mathrm{e}, \mathrm{i}, \mathrm{o}, \mathrm{s}$ ). On the other hand, the nucleolus has a strong positive reaction and the chorium, when present, presents a moderate positivity (Fig. 4a, e, i, o, s).

Group II

Results also show a great amount of proteins, seen through the strongly positive reaction in most oocytes from individuals who underwent this concentration of dinotefuran. Oocytes I, II, and III, besides the morphological and histochemical characteristics described in the control group, also have small cytoplasmic areas negative to the test located especially around the germ vesicle and next to the pedicel (Fig. 4b, f, j). In oocytes IV and V, no modifications regarding the control group were found (Fig. 4p, t).

Group III

The use of this histochemical test shows the presence of protein elements in a smaller quantity compared to those 
Fig. 6 Histological sections of dinotefuran-treated

Rhipicephalus sanguineus

midgut. a-p Baker staining. a, e, $\mathbf{i}, \mathbf{m}$ Control group. $\mathbf{b}, \mathbf{f}, \mathbf{j}, \mathbf{n}$

Group II (5000 ppm). c, $\mathbf{g}, \mathbf{k}, \mathbf{o}$

Group III (6250 ppm). d, h, l, p

Group IV (8334 ppm). $s d c$ sessile digest cells, $r d c$ residual sessile digest cells, $d d c$ detached digest cells, $l$ lumen, $m$ muscular tissue, stc stem cells (generative cells), $n$ nuclei, $p m$ plasmic membrane, $v$ vacuoles. Bars: $\mathbf{a}-\mathbf{c}=200 \mu \mathrm{m}$; $\mathbf{d}=100 \mu \mathrm{m} ; \mathbf{e}-\mathbf{h}=100 \mu \mathrm{m}$; $\mathbf{i}-\mathbf{I}=50 \mu \mathrm{m} ; \mathbf{m}-\mathbf{p}=20 \mu \mathrm{m}$
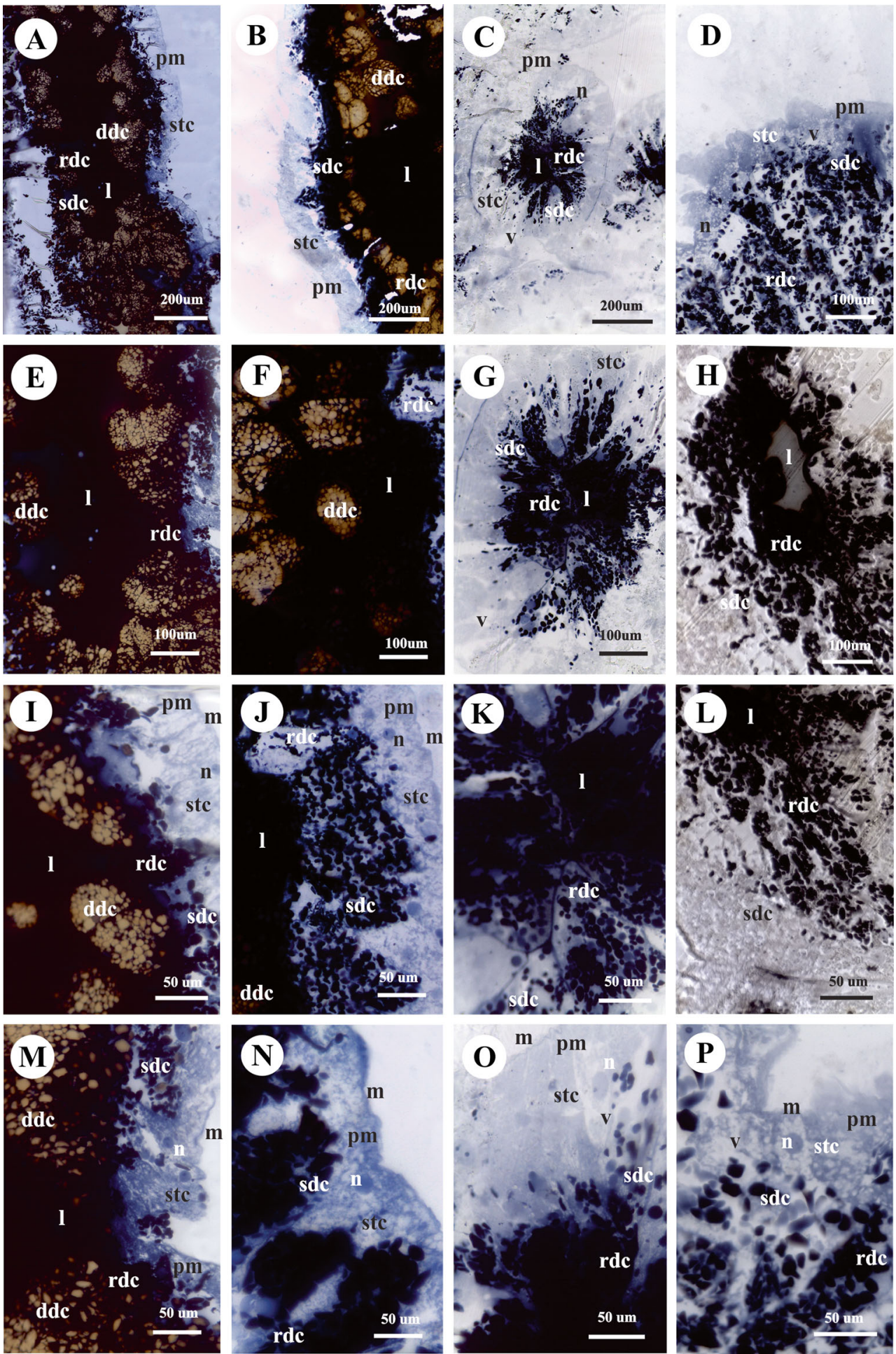

found in the other groups. Positive reactions similar to those from the control group and group II, an advance in the vacuolation process was also seen. In oocytes I, II, and III, larger vacuolated areas negative to the test were found (Fig. 4c, g, m, k). On the other hand, the oocytes IV show strong positivity in the largest part of its cytoplasm, with the exception of small vacuolated areas negative to the test near the germ vesicle and pedicel (Fig. 4q). In oocytes $\mathrm{V}$, large yolk granules with lower positivity and few vacuoles negative to the test were seen in the region near the cell periphery (Fig. 4u).

Group IV

This test shows the high decrease in the quantity of proteins in the oocytes of semi-engorged females exposed to 
8334 ppm dinotefuran. Oocytes I, II, and III present extensive areas with large and numerous vacuoles that are negative to test, occupying great part of the cytoplasm (Fig. 4d, h, 1, n). Oocytes IV have strongly positive yolk granules among the vacuoles that are negative to the test, located preferably through the regions near the germ vesicle and the pedicel (Fig. 4r). Oocytes V show great yolk granules still strongly positive to proteins, despite the marking be lower than that one found in oocytes V from the control group, as well as small vacuoles negative to test in the cell peripheral region (Fig. 4v).

With regard to the wall of the ovary, it now reacted weakly to the test.

\section{Midgut}

Control group Through this histochemical test, a moderate marking for proteins in the midgut of semi-engorged females is seen.

The generative cells present round and slightly stained regions distributed through the cytoplasm, and there is a moderate positive plasmic membrane that limits its content (Figs. 7a, i).

The digestive cells, sessile digest cells and residual sessile digest cells, show a different reaction depending on the cell region. Numerous and large endosomes and digestive vacuoles of strong to moderate positivity are located in the basal region, while the ones with weak positivity are in the apical region of cells towards the midgut lumen (Fig. 7a, i). The detached digest cells are very frequent and seen in the lumen, presenting many endosomes, digestive vacuoles, and residual bodies of hematin that are weakly positive or even negative at the test (Fig. 7a, e, i). The nucleus of digestive cells is covered (Fig. 7a, e, i). The plasmic membrane of all the digestive cells evidences moderate positivity (Fig. 7a, e, i).

The nucleus of generative (stem cells) and muscular cells, as well as the basal membrane, also reacted moderately in the test (Fig. 7a, e, i).

The lumen of individuals from the control group presents strong positivity. Only in the regions occupied by the detached digest cell, apical projection of residual sessile digest cells, and digestive residues, there were regions that were negative to the test (Fig. 7a, e, i).

Group II The histochemical test for detection of proteins highlights the moderate quantity of this element in almost all the midgut cells of semi-engorged females treated with $5000 \mathrm{ppm}$, as it was seen in individuals from the control group. Even the detached digest cells continue presenting several endosomes, digestive vacuoles, and residual bodies of hematin that are weakly positive or negative at the test (Fig. 7b, f, g).
Group III This test reveals lower positivity to the test in midgut cells of semi-engorged females from group III, indicating a decrease of proteins in this organ when compared to other groups. These changes are translated through the presence of some vacuoles of several sizes that are negative to the test in the cytoplasm of generative cells (stem cells) (Fig. 7c, g, k), as well as through endosomes and digestive vacuoles that are less frequent and moderately stained of digestive cells, sessile digest cells and residual sessile digest cells (Fig. 7c, g, k). In this group, these cells started reacting homogeneously to the test throughout its entire extension (Fig. 7c, g, k). The digestive cells, detached digest cells, are hardly detected, but they also accumulate a smaller amount of endosomes, digestive vacuoles, and weak positive residual bodies of hematin. The lumen is reduced with little blood, but including apical projections of the digestive cells, residual sessile digest, with endosomes and digestive vacuoles of moderate positivity (Fig. 7c, g, k).

Group IV Results show the smaller amount of proteins in the cells of the midgut from semi-engorged treated females that belong to group IV (Fig. 7d, h, l).

The shape of generative cells (stem cells) becomes irregular, and vacuolated areas that are negative to the test, with several sizes and shapes, are found in the cytoplasm (Fig. 7d, h, l).

In digestive cells, sessile digest cells and residual sessile digest cells, less endosomes and digestive vacuoles are found with a moderate positive reaction (Fig. $7 \mathrm{~d}, \mathrm{~h}, 1$ ).

The identification of detached digest cells is no longer possible.

The lumen of midgut does not present blood and seems to have been filled by digestive cells with endosomes and digestive vacuoles that react moderately to the test (Fig. $7 \mathrm{~d}, \mathrm{~h}, \mathrm{l}$ ).

\section{Discussion}

The $R$. sanguineus tick is a species of great medicalveterinarian importance for being the transmitting agent of several pathogens to its hosts, including men, and for causing great damages in these hosts due to the blood spoliation and skin lesions (Balashov 1983; Wall and Shearer 1997).

Chemical control (via synthetic acaricides) is still the main method to control ticks. However, the indiscriminate use of acaricides from different chemical groups has established a severe resistance case of ticks with regard to these drugs, making these ectoparasites hard to control. In parallel, another great problem is the environmental impact that has been caused due to such use and that encourages the search for new substances and/or improvement of usual substances with important characteristics, such as the low toxicity for mammals (Oliveira et al. 2013). 
Fig. 7 Histological sections of dinotefuran-treated

Rhipicephalus sanguineus midgut. a-I Bromophenol blue staining. a, e, i Control group. b, $\mathbf{f}$, j Group II (5000 ppm). c, $\mathbf{g}, \mathbf{k}$ Group III (6250 ppm). d, h, l, Group IV (8334 ppm). $s d c$ sessile digest cells, $r d c$ residual sessile digest cells, $d d c$ detached digest cells, $l$ lumen, $m$ muscular tissue, stc stem cells (generative cells), $n$ nuclei, $p m$ plasmic membrane, $v$ vacuoles. Bars: $\mathbf{a}-\mathbf{d}=100 \mu \mathrm{m}$; $\mathbf{e}-\mathbf{I}=50 \mu \mathrm{m}$
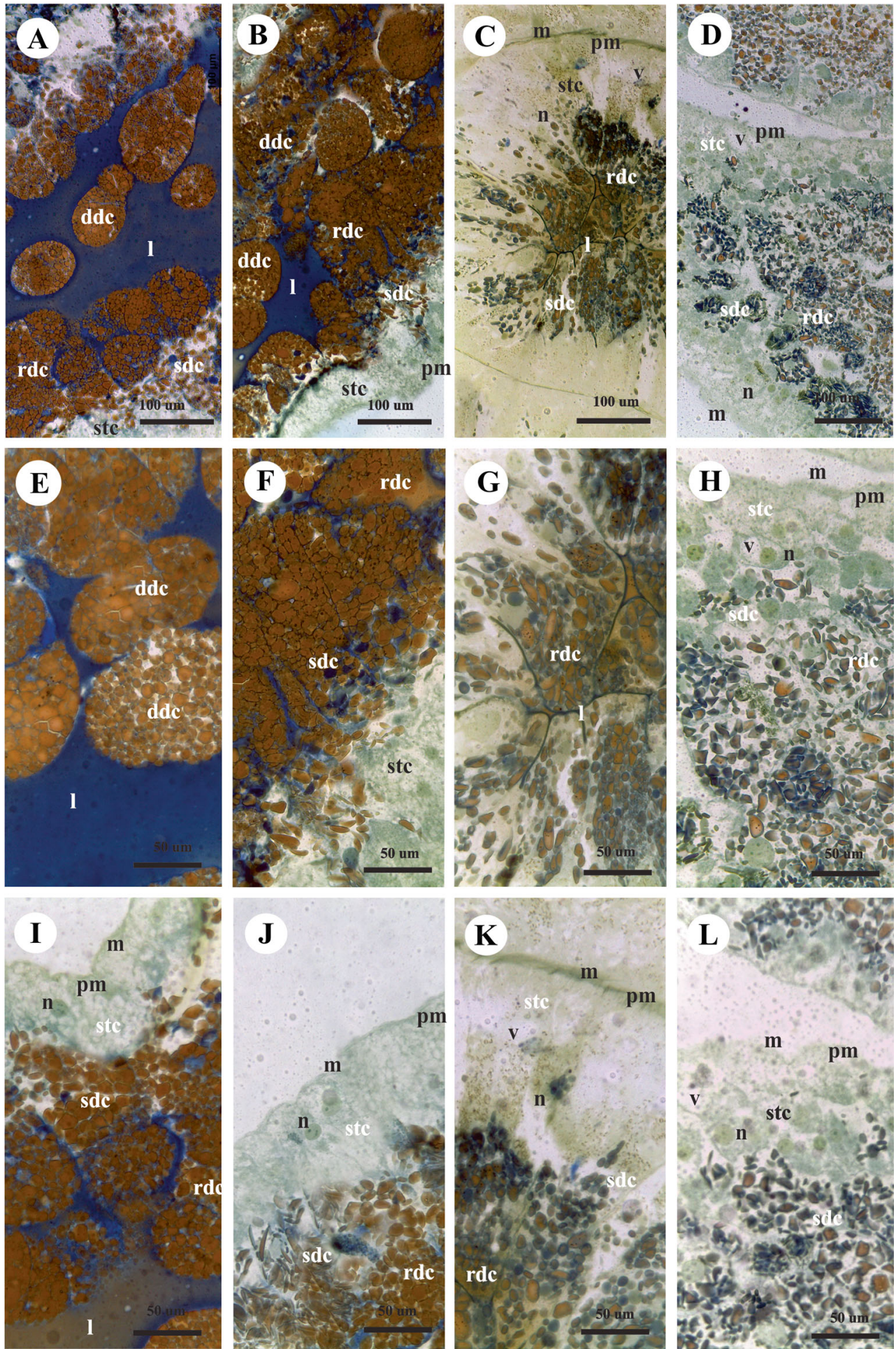

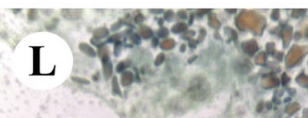

L

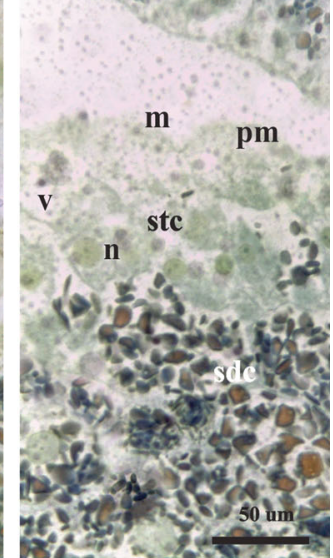

A category including substances with the potential to control these plagues are the neonicotinoids, presenting high selectivity through the nicotinic receptors of insect acetylcholine, low toxicity for mammals, and excellent chemical and biological properties (Nauen and Bretschneider 2002). One of the most important neonicotinoids is the dinotefuran, which is the most recent neonicotinoid that belongs to the third generation (Wakita et al. 2003).

Based on the above information and on the fact that $R$. sanguineus tick became an important urban pest, as well as of great interest to the general community, the present 
study verified the effects of different concentrations dinotefuran (active ingredient of Protetor Pet ${ }^{\circledR}$ acaricide) in female germ cells (oocytes) and in the midgut epithelium of semi-engorged $R$. sanguineus female ticks through morphological, histological, and histochemical study in order to detect the occurrence of possible damages in these cells. Therefore, we tried to find if the interference in the genesis of new individuals and food absorption ingested and deriving from the host occurred, which may provide essential information that will contribute for the development of new control methods and/or improvement of the usual control methods.

The individuals of the treatment groups II, III, and IV were exposed to 5000, 6250, and $8334 \mathrm{ppm}$ of dinotefuran and revealed the action of this compound showing changes in ovaries and midgut cells of semi-engorged females of the different groups, which were compared with those of group I (control). The alterations were mainly related to the size of the germ cells and yolk granules; presence, quantity, size, and location of vacuoles found in the cytoplasm of these germ cells; the damage occurred in the generative cells of the midgut; the size of the digestive cells; the quantity of blood elements captured, accumulated digestive wastes and digestive vacuoles found in the cytoplasm of the digestive cells of the midgut, as well as the quantity and distribution of proteins, polysaccharides, lipids of all cells in both.

The ovary of semi-engorged $R$. sanguineus females of the control group presents characteristics previously described by Oliveira et al. (2005). The ovary is composed of a wall of epithelial cells and of a great number of oocytes in five stages of development, which are attached to the wall of the ovary through a cellular pedicel, corroborating to data obtained by Till (1961) in Rhipicephalus appendiculatus, Balashov (1983) in Hyalomma asiaticum, Denardi et al. (2004) in Amblyomma cajennense, Saito et al. (2005) in B. microplus. Only Amblyomma triste species has oocytes in four development stages (Oliveira et al. 2006).

The oocytes in all development stages of the control group show morphological characteristics typical of the ticks' oocytes and that have also been described for other tick species (Denardi et al. 2004; Saito et al. 2005; Oliveira et al. 2005, 2006). Thus, in the present study, the characteristics of oocytes from the control group are little approached with the discussion only of their alterations upon the use of dinotefuran.

The oocytes I of females exposed to $5000 \mathrm{ppm}$ (group II) and $6250 \mathrm{ppm}$ (group III) of dinotefuran presented vacuoles around the germ vesicle, indicating that the dinotefuran was already beginning to function in these cells. In those exposed to $8334 \mathrm{ppm}$ (group IV), there was an increase of alterations, since several vacuoles were found occupying a great part of the cytoplasm. This evidences that when dinotefuran concentrations increase, the number of damages seen in oocytes I from semi-engorged treated females of $R$. sanguineus also increase. These data suggest that chorium absence (a membrane to protect the eggs and that is still not deposited in oocytes in the early stages of development) could be enabling the high chemical input efficiency through the plasmic membrane of this germ cell, once inside it would damage the cell, as reported by Oliveira et al. (2009); Roma et al. (2010); Vendramini et al. (2012) in $R$. sanguineus ticks exposed to fipronil, permethrin, and andiroba oil, respectively.

Oocytes II from females exposed to $5000 \mathrm{ppm}$ of dinotefuran (group II) show few and small vacuoles occupying the region near the germ vesicle or surrounding the entire germ vesicle. Individuals exposed to $6250 \mathrm{ppm}$ of dinotefuran (group III) have large vacuolated regions around the germ vesicle and in the periphery towards the pedicel. In those exposed to $8334 \mathrm{ppm}$ dinotefuran (group IV), an extensive vacuolation in more than $50 \%$ of the cell is found, especially in regions near the pedicel, which confirm the occurrence of greater damages caused by the higher concentration of this chemical. These alterations may have been caused by the dinotefuran, since this chemical could be damaging cell organelles and these being wrapped and lysed in vacuoles.

Carvalho and Recco-Pimentel (2012) and Junqueira and Carneiro (2013) reported that autophagic vacuoles would be observed especially in cells where there were degradation and recycling processes of cytoplasm portions and/or damaged organelles happening, which would justify the presence and increase of these organelles in oocytes II of treated individuals.

Furthermore, the high vacuolation of the oocytes II of group IV quite restricts the area occupied by yolk granules, and this decrease in the quantity of granules could partially or completely harm their development and, thus, not allow their advance to more advanced stages of development (III, IV, and V). Other studies performed by Oliveira et al. (2009) also observed the occurrence of great damages in oocytes II from females of $R$. sanguineus exposed to a higher concentration of fipronil, where both the vacuolation and decrease in the number of microvilli were found. In the present study, a smaller number of microvilli in the plasmic membrane of oocytes II exposed to the concentration of $8334 \mathrm{ppm}$ of dinotefuran could also be happening. This would compromise the exogenous incorporation (production of yolk elements by other tissues that would be transported through the hemolymph until the ovary and would be absorbed through the oocyte via pinocytic vesicles) and explain the lower amount of yolk granules found in the cytoplasm of these germ cells.

In oocytes III of the individuals exposed to $5000 \mathrm{ppm}$ of dinotefuran (group II), vacuolated areas around the germ vesicle were found in the periphery towards the pedicel and among the yolk granules. Individuals exposed to the $6250 \mathrm{ppm}$ (group III) and $8334 \mathrm{ppm}$ (group IV) of dinotefuran presented oocytes III with higher vacuolation especially in regions near the pedicel. These data indicate that dinotefuran 
is really damaging these cells. Since the greatest damage happened in regions near the pedicel and this structure is responsible for attaching the oocytes to the wall of the ovary (Denardi et al. 2004; Saito et al. 2005; Oliveira et al. 2005, 2006), synthesizing and/or providing yolk elements to the growth of these germ cells (Oliveira et al. 2007), maybe dinotefuran is also being captured from the hemolymph and taken to the interior of the oocyte via pedicel.

Friesen and Kaufman (2003), in studies performed with Amblyomma hebraeum, reported that cypermethrin, a pyrethroid chemical, inhibited the uptake of vitellogenin (most abundant protein in the yolk) from the hemolymph through the oocyte, which caused a decrease in the quantity of vitellogenin available inside the oocytes. In view of this, the oocytes from these treated animals did not grow so much or formed bigger granules in the yolk. In the present study, this process may have also happened, since the presence of smaller treated yolk granules in oocytes III treated with $8334 \mathrm{ppm}$ dinotefuran (group IV) than those found in the control group and in other treatment groups II and III was observed. Sayah et al. (1996) also found similar results in Labidura riparia insect subjected to treatment with Azadirachta indica, and Lemos et al. (2005) found in Supputius cincticeps insect in the treatment with permethrin.

In oocytes III from individuals treated with 5000, 6250, and $8334 \mathrm{ppm}$ of dinotefuran, a progressive increase of cytoplasmic vacuolation when the oocytes of groups II, III, and IV were compared was also seen. This could indicate again that dinotefuran in higher concentrations would be compromising the oocytes more, and therefore, more intense autophagic processes would be happening, in an attempt to eliminate a higher amount of damaged elements from these germ cells. Denardi et al. (2010) also described this process.

The oocytes in more advanced stages of development, i.e., oocytes IV and V did not suffer very extensive damages as those in the early stages of development. In group II of treatment, these oocytes were not affected. In group III, rare changes in these oocytes were seen despite some folds in the wrap and rare vacuoles. Otherwise, in individuals exposed to a concentration of $8334 \mathrm{ppm}$ of dinotefuran (group IV) were found vacuoles among yolk granules of the oocytes IV, and in the oocytes $\mathrm{V}$, there were wrap folds as well as less dense yolk granules in the central region and ruptured, besides the vacuoles in the periphery. Therefore, if oocytes in the early stages of development were able to survive trying to promote the protein synthesis, although in lower scale, they may also be affected by dinotefuran in more late stages of development (IV and V). These data can be explained by the presence of chorium, a membrane deposited in the plasmic membrane of these oocytes (Oliveira et al. 2005), which is responsible for preserving the structure of the future embryo and consequently of the species (King and Vanoucek 1960), to protect the eggs against mechanical shocks and temperature variation, to avoid desiccation, to minimize predation, and especially to promote gaseous exchanges (Hilton 1982). Since this membrane is considered resistant and represents another barrier to be transposed by dinotefuran, i.e., lower permeability of the membrane, it has probably compromised the efficiency of the chemical entrance to these oocytes from the treated individuals. Oliveira et al. (2008) and Roma et al. (2010) also reported the occurrence of this process.

The wall of the ovary of semi-engorged $R$. sanguineus females was only damaged in individuals exposed to $8334 \mathrm{ppm}$ of dinotefuran. The epithelium, rather than being represented by small cuboidal cells with rounded nuclei as it was in the previous groups, is now extremely fragile and delicate, showing vacuolated cells with flattened morphology and pyknotic nucleus. These data may indicate the occurrence of apoptosis (Nodari et al. 2011) or autophagy (Oliveira et al. 2012) in the individuals exposed here. However, as the cells are trying to survive and resist any external agents and/or aggressors, it is suggested that oocytes and the epithelial wall of the ovary would only be removing the chemical dinotefuran and/or the areas that were lesioned and damaged by it, a process called autophagy. The apoptotic cell death would only occur after the autophagy, when the repair is no longer possible (Kang et al. 2011). As these cells are damaged, they cannot carry out their functions properly, such as forming the pedicel, providing elements to constitute the yolk granules, and contributing to the growth and development of germ cells. Thus, dinotefuran may be reducing the number of mature oocytes, i.e., the ones that completed the vitellogenesis process. Therefore, with its use, there would be less number of oocytes available for ovulation, which would affect female fertility and, as result, the fertility of the entire species.

Studies conducted by Friesen et al. (2003) showed the activity of avermectin in oocytes of the A. hebraeum tick and reported that this chemical agent would induce the interruption of the vitellogenesis and the degeneration of the yolk in the oocytes of individuals subjected to the treatment, which corroborates data obtained in the present study regards to the activity of dinotefuran in oocytes of $R$. sanguineus.

Another parameter that could be assessed would be the size of oocytes of individuals treated with dinotefuran. All oocytes from group IV, that is, those who were exposed to $8334 \mathrm{ppm}$ dinotefuran showed a smaller diameter than the control group and the treatment groups II and III, as a result of the action of dinotefuran. Other studies carried out by Davey et al. (1998) and by Friesen and Kaufman (2003) also indicated a reduction in the size of oocytes of $R$. (Boophilus) microplus exposed to fipronil and in A. hebraeum exposed to treatment with cypermethrin.

Through the use of histochemical techniques, the presence of polysaccharides, proteins, and lipids was detected in the ovary of semi-engorged females from the control group and the treatment groups. 
The presence of polysaccharides, proteins, and lipids in oocytes from individuals in the control group is similar to that already described by Oliveira et al. (2005), namely, the high amount of all elements in all oocytes. With the exception of oocyte I, which showed weak positive reaction to PAS and bromophenol blue, as well as moderate positive reaction to Baker. In the present study, the treatment of females with different concentrations of dinotefuran resulted in the gradual and progressive decrease of all elements in oocytes I, II, III, and IV, especially due to the presence of vacuoles in large areas of the cytoplasm (I-IV) and the lowest growth of yolk granules that were formed during vitellogenesis. However, in the $\mathrm{V}$ oocytes, in addition to the damages mentioned above being observed, it is evident the lower positivity detected in large yolk granules on test for proteins, polysaccharides and lipids, which makes it clear that the synthesis and/or storage of the three elements by the germ cells from $R$. sanguineus females of the treatment groups (groups II, III, and IV) are occurring with disabilities. In view of this, the germ cells that are being formed may no longer be able, or to advance in their development, or even to originate a new individual. Watermann et al. (2013) found similar data, on the copepod Acartia tonsa exposed to methyltestosterone, once the yolk composition was altered after being exposed to the chemical.

Another organ that was also used as a tool to understand the action of the chemical dinotefuran was the midgut. The midgut of semi-engorged $R$. sanguineus females of the control group presented epithelial wall composed of different cell types and supported on a basal membrane and on a thin layer of muscle tissue, corroborating data obtained by Till (1961), Balashov (1983), Agbede and Kemp (1985), Koh et al. (1991), Sonenshine (1991), Agyei and Runham (1995), and Harrison and Foelix (1999) in other tick species.

Other authors have already made excellent descriptions about morphology, histology, and midgut physiology of ticks. In view of this, more informations can be seen elsewhere (Agbede and Kemp 1985; Walker and Fletcher 1987; Koh et al. 1991; Sonenshine 1991; Agyei and Runham 1995; Harrison and Foelix 1999; Remedio et al. 2013).

In the midgut of the semi-engorged females exposed to $5000 \mathrm{ppm}$ of dinotefuran, morphological changes were not detected. In females exposed to $6250 \mathrm{ppm}$ of dinotefuran, alterations have already been observed in a few generative cells (stem cells), in all stages of the digestive cells and lumen, which demonstrates that the dinotefuran started to affect those cells. The digestive cells, sessile digest cells and the residual sessile digest cells, are more designed towards the lumen and have less endosomes and digestive vacuoles in the cytoplasm. Detached digest cells are no longer so evident, and less endosomes, digestive vacuoles, and hematin residual bodies are also found in their cytoplasm. This data can be justified by the action of dinotefuran in the midgut cells, causing damages in these cells and interfering in the digestive processes of the animals exposed. Thus, the midgut cells could be suffering lesions by contact with chemical, which would decrease the efficiency of these cells when performing their functions of capturing of blood ingested during the blood meal, lysis of blood cells in digestive vacuoles, formation of digestive residues, and release of nutrients after the digestion processes (Agbede and Kemp 1985; Koh et al. 1991; Agyei and Runham 1995). The occurrence of this process was also observed by Borges et al. (2004) and Valotto et al. (2011), since the midgut epithelial cells of $A$. aegypti larvae were damaged after exposure to diflubenzuron and the crude ethanolic extract of the Sapindus saponaria Lin (Sapindaceae) plant, respectively.

In females of group IV, morphological changes were found. The disorganization in stem cells, in digestive cells and midgut lumen, is intense. The stem cells become irregular and twisted, and the cytoplasmic vacuolization advances mainly in the basal region of the cell and that next to the digestive cells. As these cells are responsible for the renewal of the epithelium with formation of all other types of cells existent in the midgut (Agbede and Kemp 1985; Harrison and Foelix 1999) and were here damaged by exposure to chemical, it is suggested that there will be no more replacement of the cells that were released from the basal membrane during the digestion process nor those digestive cells that were also damaged by the action of dinotefuran, which would imply high loss for the digestion process.

In the sessile digest cells and residual sessile digest cells, few endosomes and digestive vacuoles were detected compared to previous groups, as well as extensive apical cytoplasmic projection and absence of cytoplasmic limits. Detached digest cells were not even found in this group. These data are indicators that the dinotefuran is damaging the midgut cells of these ectoparasites that have been treated, probably due, or the contact of the midgut cells with the highest concentration of the chemical, or even by being absorbed into the interior of these cells along with the blood. The digestive cells that have been damaged may no longer be able to perform all of their functions, which would compromise the digestive processes and the release of blood nutrients necessary for the nutrition of the ectoparasites, in other words, the body's metabolism and the viability of the individual itself. Similar results were obtained by Valotto et al. (2011) for A. aegypti larvae subjected to the natural compound obtained of Magonia pubescens (Sapindaceae) and by Scudeler and Santos (2013) for Ceraeochrysa claveri larvae after treatment with neem oil.

Studies by Tomizawa and Casida (2005) documented that the dinotefuran acts on the central nervous system of exposed individuals. This chemical agonistically binds to the postsynaptic nicotinic acetylcholine receptors, but the acetylcholinesterase enzyme cannot degrade the dinotefuran, and keeps it connected to the receptor and also opens the $\mathrm{Na}+$ ion channels which move into the cell, depolarizing it, causing extended, 
continuous, and uncontrolled nerve impulse (Kagabu 1997; Uneme et al. 1999; Wakita et al. 2003, 2005; Wakita 2011). In the present study, it is demonstrated that, in addition to its neurotoxic effects, dinotefuran has also affect other systems of arthropods.

The use of histochemical techniques of bromophenol blue and Baker allowed observing the high quantity of proteins and lipids in most cells of the midgut of semi-engorged $R$. sanguineus females of the control group. It only occurred weakly positive or negative reaction in the residual hematin bodies found in the detached digest cells. In the females of group II, there were no histochemical alterations detected after the treatment with dinotefuran. In those from group III and IV, dinotefuran provoked the gradual reduction in the quantity of lipid and protein elements since the increase of vacuolated areas (negative to the tests) and decrease in the number of endosomes and digestive vacuoles positive to the tests occurred. In view of this, it was observed that the dinotefuran is harming the capture and efficient and complete digestion of blood through the midgut cells of the treated animals, which will result in the lack of nutrients needed to maintain the normal function of all physiological systems. In advanced stages, that "under nutrition" will lead the ectoparasite to death. Other studies by Scudeler et al. (2014) also detected the appearance of the histochemical alterations in the midgut of C. claveri larvae treated with neem oil.

In this way, it was verified through the results obtained by the present study, the occurrence of progressive damage caused by the dinotefuran in the germ cells and midgut cells in semi-engorged $R$. sanguineus females ticks. The concentrations that were applied are preventing partially or even completely the digestive processes and, without this appropriate nutrition, no physiological events of the ectoparasites will be able to occur, and these will not even be able to grow and develop. As for the germ cells, these were also committed and probably will no longer be able to advance in its development (I-V) and complete the vitellogenesis process, which will affect the fertility of the female by no longer give rise to a new individual. Therefore, it has demonstrated the effectiveness of dinotefuran in the reduction of fertility and digestive processes of semi-engorged $R$. sanguineus females.

Acknowledgments We would like to thank to CNPQ for financial support, PNPD for financial support, and CNPQ academic career research fellowship to G.H. Bechara and M.I. Camargo-Mathias.

\section{References}

Agbede R, Kemp D (1985) Digestion in the cattle-tick Boophilus microplus: light microscope study of the gut cells in nymphs and females. Int J Parasitol 15:147-157. doi:10.1016/0020-7519(85) 90080-3
Agyei A, Runham N (1995) Studies on the morphological changes in the midguts of two ixodid tick species Boophilus microplus and Rhipicephalus appediculatus during digestion of the blood meal. Int J Parasitol 25:55-62. doi:10.1016/0020-7519(94)00114-4

Baker J (1946) The histochemical recognition of lipine. Q J Microsc Sci 87:441-4470

Balashov Y (1983) The female reproductive system. In: Balashov YS (ed) An atlas of ixodid tick ultrastructure. Entomological Society of America, Russia, pp 98-128

Bechara GH, Szabó JM, Ferreira B, Garcia M (1995) Rhipicephalus sanguineus tick in Brazil: feeding and reproductive aspects under laboratorial conditions. Braz J Vet Parasitol 4:61-66

Borges A, Cavasin G, Silva I et al (2004) Mortalidade e alterações morfológicas provocadas pela ação inibidora do diflubenzuron na ecdise de larvas de Aedes aegypti (Diptera, Culicidae). Rev Patol Trop 33:91-104

Carvalho HF, Recco-Pimentel SM (2012) A Célula, $3^{\mathrm{a}}$ edn. Editora Manole, São Paulo

Corbel V, Duchon S, Zaim M, Hougard JM (2004) Dinotefuran: a potential neonicotinoid insecticide against resistant mosquitoes. J Med Entomol 41:712-7

Coutinho MTZ, Bueno LL, Sterzik A et al (2005) Participation of Rhipicephalus sanguineus (Acari: Ixodidae) in the epidemiology of canine visceral leishmaniasis. Vet Parasitol 128:149-155. doi: 10.1016/j.vetpar.2004.11.011

Craig T (1990) Infectious diseases of the dog and cat. W.B. Saunders Co, Philadelphia

Crampton A, Baxter G, Barker S (1999) Identification and characterisation of a cytochrome $\mathrm{P} 450$ gene and processed pseudogene from an arachnid: the cattle tick, Boophilus microplus. Insect Biochem Mol Biol 29:377-384. doi:10.1016/S0965-1748(99)00013-2

Davey RB, Ahrens EH, George JE et al (1998) Therapeutic and persistent efficacy of fipronil against Boophilus microplus (Acari: Ixodidae) on cattle. Vet Parasitol 74:261-276

Denardi SE, Bechara GH, de Oliveira PR et al (2004) Morphological characterization of the ovary and vitellogenesis dynamics in the tick Amblyomma cajennense (Acari: Ixodidae). Vet Parasitol 125:379_ 95. doi:10.1016/j.vetpar.2004.07.015

Denardi SE, Bechara GH, de Oliveira PR, Camargo-Mathias MI (2010) Azadirachta indica A. Juss (neem) induced morphological changes on oocytes of Rhipicephalus sanguineus (Latreille, 1806) (Acari: Ixodidae) tick females. Exp Parasitol 126:462-70. doi:10.1016/j. exppara.2010.05.017

Dryden MW, Payne PA, Vicki SR, Kobuszewski D (2011) Efficacy of topically applied dinotefuran formulations an orally administered spinosad tablets against the KS1 Flea strain infesting dogs. Int J Appl Res Vet Med 9:124-129

EPA (2009) Pesticides and toxic substances: pesticide fact sheet dinotefuran. EPA PC Code 044312. www.epa.gov/ opprd001/ factsheets/dinotefuran.pdf. Accessed 1 Mar 2009

French TW, Harvey JW (1983) Serologic diagnosis of infectious cyclic thrombocytopenia in dogs using an indirect fluorescent antibody test. Am J Vet Res 44:2407-2411

Friesen KJ, Kaufman WR (2003) Cypermethrin inhibits egg development in the ixodid tick, Amblyomma hebraeum. Pestic Biochem Physiol 76:25-35. doi:10.1016/S0048-3575(03)00032-4

Friesen KJ, Suri R, Kaufman WR (2003) Effects of the avermectin, MK-243, on ovary development and salivary gland degeneration in the ixodid tick, Amblyomma hebraeum. Pestic Biochem Physiol 76:82-90. doi:10.1016/S0048-3575(03)00070-1

González A, D del Castro C, González S (2004) Ectoparasitic species from Canis familiaris (Linné) in Buenos Aires province, Argentina. Vet Parasitol 120:123-9. doi:10.1016/j.vetpar.2003.12.001

Harrison W, Foelix R (1999) Chelicerata: Arthropoda. In: Harrison W, Foelix R (eds) Microscopic anatomy of invertebrates. Wiley-Liss, New York, NY 
Hilton H (1982) Biology of insect egg shells. Pergamon, Oxford

Junqueira LC, Carneiro J (2013) Histologia Básica. Guanabara Koogan, Rio de Janeiro

Junqueira LCU, Junqueira LMMS (1983) Técnicas básicas de citologia e histologia. Livraria Editora Santos, São Paulo

Kagabu S (1997) Chloronicotinyl insecticides-discovery, application and future perspective. Rev Toxicol 1:75-129

Kang R, Tang D, Lotze MT, Zeh HJ (2011) RAGE regulates autophagy and apoptosis following oxidative injury. Autophagy 7:442-444

King RC, Vanoucek EG (1960) Oogenesis in adult Drosophila melanogaster. X. Studies on the behavior of the follicle cells. Growth 24:333-338

Kiriyama K, Nishimura K (2002) Structural effects of dinotefuran and analogues in insecticidal and neural activities. Pest Manag Sci 58: 669-676. doi:10.1002/ps.493

Koh K, Mori T, Shiraishi S, Uchida TA (1991) Ultrastructural changes of the midgut epithelial cells in feeding and moulting nymphs of the tick Haemaphysalis longicornis. Int J Parasitol 21:23-36

Labruna M, Pereira M (2001) Carrapato em Cães no Brasil. Clín Vet 30: 24-32

Lemos WP, Medeiros RS, Zanuncio JC, Serrão JE (2005) Effect of sublethal concentrations of permethrin on ovary activation in the predator Supputius cincticeps (Heteroptera: Pentatomidae). Braz J Biol 65:287-290. doi:10.1590/S1519-69842005000200012

Linardi PM, Nagem RL (1973) Pulicídeos e outros ectoparasitos de cães de Belo Horizonte e municípios vizinhos. Rev Bras Biol 33:529-538

McManus JFA (1948) Histological and histochemical uses of periodic acid. Stain Technol 23:99-108

Merle C, Sotto A, Barbuat C, Jourdan J (1998) Disease course of Mediterranean Spotted Fever: remark on 16 cases. In: 7e Colloque sur le Controle Epidemiologique des Maladies Infectieuses. pp 400-401

Nauen R, Bretschneider T (2002) New modes of action of insecticides. Pestic Outlook 13:241-245. doi:10.1039/b211171n

Nodari EF, Roma GC, Furquim KCS et al (2011) Cytotoxic effects of permethrin in salivary glands of Rhipicephalus sanguineus (Latreille, 1806) (Acari: Ixodidae) semi-engorged females. Exp Parasitol 128:151-158. doi:10.1016/j.exppara.2011.02.003

Nolan J (1985) Mechanisms of resistance to chemicals in arthropod parasites of veterinary importance. Vet Parasitol 18:155-166

Oliveira PR, Bechara GH, Denardi SE et al (2005) Morphological characterization of the ovary and oocytes vitellogenesis of the tick Rhipicephalus sanguineus (Latreille, 1806) (Acari: Ixodidae). Exp Parasitol 110:146-156. doi:10.1016/j.exppara.2004.12.016

Oliveira PR, Camargo-Mathias MI, Bechara GH (2006) Amblyomma triste (Koch, 1844) (Acari: Ixodidae): morphological description of the ovary and of vitellogenesis. Exp Parasitol 113:179-185. doi:10. 1016/j.exppara.2006.01.012

Oliveira PR, Camargo-Mathias MI, Bechara GH (2007) Vitellogenesis in the tick Amblyomma triste (Koch, 1844) (Acari: Ixodidae) Role for pedicel cells. Vet Parasitol 143:134-139. doi:10.1016/j.vetpar.2006. 08.013

Oliveira PR, Bechara GH, Camargo-Mathias MI (2008) Evaluation of cytotoxic effects of fipronil on ovaries of semi-engorged Rhipicephalus sanguineus (Latreille, 1806) (Acari: Ixodidae) tick female. Food Chem Toxicol 46:2459-2465. doi:10.1016/j.fct. 2008.03.034

Oliveira PR De, Bechara GH, Morales MAM, Mathias MIC (2009) Action of the chemical agent fipronil on the reproductive process of semi-engorged females of the tick Rhipicephalus sanguineus (Latreille, 1806) (Acari: Ixodidae). Ultrastructural evaluation of ovary cells. Food Chem Toxicol 47:1255-1264. doi:10.1016/j.fct.2009. 02.019
Oliveira PR, Bechara GH, Denardi SE et al (2012) Cytotoxicity of fipronil on mice liver cells. Microsc Res Tech 75:28-35. doi:10. $1002 /$ jemt. 21018

Oliveira PR, Calligaris IB, Roma GC et al (2013) Fluazuron-induced morphophysiological changes in the cuticle formation and midgut of Rhipicephalus sanguineus Latreille, 1806 (Acari: Ixodidae) nymphs. Parasitol Res 112:45-58. doi:10.1007/s00436-012-3103-7

Pearse A (1985) Histochemistry theoretical and applied. Livingstone, Churchill

Pruett JH (1999) Immunological control of arthropod ectoparasites - a review. Int J Parasitol 29:25-32. doi:10.1016/S0020-7519(98) 00172-6

Remedio RN, Sampieri BR, Vendramini MCR et al (2013) Morphology of the midgut of Rhipicephalus sanguineus (Latreille, 1806) (Acari: Ixodidae) adult ticks in different feeding stages. Parasitol Res 112: 415-425. doi:10.1007/s00436-012-3153-x

Roma GC, Furquim KCS, Bechara GH, Camargo-Mathias MI (2010) Permethrin-induced morphological changes in oocytes of Rhipicephalus sanguineus (Acari: Ixodidae) semi-engorged females. Food Chem Toxicol 48:825-830. doi:10.1016/j.fct.2009. 12.016

Saito KC, Bechara GH, Nunes ET et al (2005) Morphological, histological, and ultrastructural studies of the ovary of the cattle-tick Boophilus microplus (Canestrini, 1887) (Acari: Ixodidae). Vet Parasitol 129:299-311. doi:10.1016/j.vetpar.2004.09.020

Sayah F, Fayet C, Idaomar M, Karlinsky A (1996) Effect of Azadirachtin on vitellogenesis of Labidura riparia (Insect Dermaptera). Tissue Cell 28:741-749. doi:10.1016/S0040-8166(96)80077-2

Scudeler EL, Santos DC (2013) Effects of neem oil (Azadirachta indica A. Juss) on midgut cells of predatory larvae Ceraeochrysa claveri (Navás, 1911) (Neuroptera: Chrysopidae). Micron 44:125-132. doi: 10.1016/j.micron.2012.05.009

Scudeler EL, Padovani CR, Dos Santos DC (2014) Effects of neem oil (Azadirachta indica A. Juss) on the replacement of the midgut epithelium in the lacewing Ceraeochrysa claveri during larval-pupal metamorphosis. Acta Histochem 116:771-780. doi:10.1016/j. acthis.2014.01.008

Sexton DJ, Burgdorfer W, Thomas L, Norment BR (1976) Rocky Mountain spotted fever in Mississippi: survey for spotted fever antibodies in dogs and for spotted fever group Rickettsiae in dog ticks. Am J Epidemiol 103:192-197

Soares AO, Souza AD, Feliciano EA et al (2006) Evaluation of ectoparasites and hemoparasites in dogs kept in apartments and houses with yards in the city of Juiz de Fora, Minas Gerais, Brazil. Rev Bras Parasitol Vet 15:13-6

Sonenshine DE (1991) The female reproductive system. In: Sonenshine DE (ed) Biology of Ticks. Oxford University Press, New York, pp 280-304

Stephen S, Chandrashekara I, Rao KN (1980) Natural occurrence of Coxiella burnetii in the brown dog tick Rhipicephalus sanguineus. Indian J Med Res 71:865-869

Szabó MP, Cunha TM, Pinter A, Vicentini F (2001) Ticks (Acari: Ixodidae) associated with domestic dogs in Franca region, São Paulo, Brazil. Exp Appl Acarol 25:909-16. doi:10.1023/ A:1020433003028

Till WM (1961) A contribution to the anatomy and histology of the brown ear tick Rhipicephalus appendiculatus Neumann. Mem Entomol Soc S Afr 6:1-124

Tomizawa M, Casida JE (2005) Neonicotinoid insecticide toxicology: mechanisms of selective action. Annu Rev Pharmacol Toxicol 45: 247-68. doi:10.1146/annurev.pharmtox.45.120403.095930

Uneme H, Iwanaga K, Higuchi N et al (1999) Synthesis and insecticidal activity of nitroguanidine derivatives. Pestic Sci 55:202-205. doi: 10.1002/(SICI)1096-9063(199902)55:2\%3<202::AID-PS869>3.0. $\mathrm{CO} ; 2-\mathrm{G}$ 
Valotto CFB, Da Silva HHG, Cavasin G et al (2011) Alterações ultraestruturais em larvas de Aedes aegypti submetidas ao diterpeno labdano, isolado de Copaifera reticulata (Leguminosae), e à uma fração rica em taninos de Magonia pubescens (Sapindaceae). Rev Soc Bras Med Trop 44:194-200. doi:10.1590/S003786822011005000010

Vendramini MCR, Camargo-Mathias MI, Faria AU et al (2012) Cytotoxic effects of andiroba oil (Carapa guianensis) in reproductive system of Rhipicephalus sanguineus (Latreille, 1806) (Acari: Ixodidae) semi-engorged females. Parasitol Res 111:1885-1894. doi:10.1007/s00436-012-3031-6

Wakita T (2011) Molecular design of dinotefuran with unique insecticidal properties. J Agric Food Chem 59:2938-2942. doi:10.1021/ jf1030778

Wakita T, Kinoshita K, Yamada E et al (2003) The discovery of dinotefuran: a novel neonicotinoid. Pest Manag Sci 59:1016-1022. doi: $10.1002 /$ ps.727

Wakita T, Yasui N, Yamada E, Kishi D (2005) Development of a novel insecticide, dinotefuran. J Pestic Sci 30:133-138. doi:10.1584/ jpestics. 30.133
Walker AR, Fletcher JD (1987) Histology of digestion in nymphs of Rhipicephalus appendiculatus fed on rabbits and cattle naive and resistant to the ticks. Int J Parasitol 17:1393-1411

Walker JB, Keirans JE, Horak IG (2000) The genus Rhipicephalus (Acari: Ixodidae). A guide to the brown ticks of the world. Cambridge University Press, London

Wall R, Shearer D (1997) Veterinary entomology. Chapman and Hall, London

Watermann BT, Albanis TA, Dagnac T et al (2013) Effects of methyltestosterone, letrozole, triphenyltin and fenarimol on histology of reproductive organs of the copepod Acartia tonsa. Chemosphere 92:544-554. doi:10.1016/j.chemosphere.2013. 03.053

Woldehiwet Z, Ristic M (1993) Rickettsial and chlamydial diseases of domestic animals. Pergamon, Oxford

Yoshinari NH, Barros PJL, Bonoldi VLN et al (1997) Perfil da borreliose de Lyme no Brasil. Rev do Hosp das Clínicas da Fac Med São Paulo 52:111-117

Zaim M, Guillet P (2002) Alternative insecticides: an urgent need. Trends Parasitol 18:161-163. doi:10.1016/S1471-4922(01)02220-6 